OPEN ACCESS

Edited by:

Sylvia Gertrud Sander,

University of Otago, New Zealand

Reviewed by:

David Turner,

University of Gothenburg, Sweden

Mona Wells,

Xi'an Jiaotong-Liverpool University,

China

${ }^{*}$ Correspondence:

Martha Gledhil

mgledhill@geomar.de

Specialty section: This article was submitted to

Marine Biogeochemistry,

a section of the journal

Frontiers in Marine Science

Received: 12 November 2015 Accepted: 14 April 2016

Published: 29 April 2016

Citation:

Avendaño L, Gledhill M,

Achterberg EP, Rérolle VMC and Schlosser C (2016) Influence of Ocean

Acidification on the Organic Complexation of Iron and Copper in Northwest European Shelf Seas; a

Combined Observational and Model

Study. Front. Mar. Sci. 3:58.

doi: 10.3389/fmars.2016.00058

\section{Influence of Ocean Acidification on the Organic Complexation of Iron and Copper in Northwest European Shelf Seas; a Combined Observational and Model Study}

\author{
Lizeth Avendaño $^{1}$, Martha Gledhill ${ }^{1,2 *}$, Eric P. Achterberg ${ }^{1,2}$, Victoire M. C. Rérolle ${ }^{1}$ and \\ Christian Schlosser ${ }^{1,2}$ \\ ${ }^{1}$ Ocean and Earth Science, National Oceanography Centre, University of Southampton, Southampton, UK, ${ }^{2}$ GEOMAR \\ Helmholtz Centre for Ocean Research Kiel, Kiel, Germany
}

The $\mathrm{pH}$ of aqueous solutions is known to impact the chemical speciation of trace metals. In this study we conducted titrations of coastal seawaters with iron and copper at $\mathrm{pH}$ 7.91, 7.37, and 6.99 (expressed on the total $\mathrm{pH}$ scale). Changes in the concentration of iron and copper that complexed with the added ligands 1-nitroso-2-napthol and salicylaldoxime respectively were determined by adsorptive cathodic stripping voltammetry-competitive ligand equilibrium (AdCSV-CLE). Interpretation of the results, assuming complexation by a low concentration of discrete ligands, showed that conditional stability constants for iron complexes increased relative to inorganic iron complexation as $\mathrm{pH}$ decreased by approximately 1 log unit per $\mathrm{pH}$ unit, whilst those for copper did not change. No trend was observed for concentrations of iron and copper complexing ligands over the $\mathrm{pH}$ range examined. We also interpreted our titration data by describing chemical binding and polyelectrolytic effects using non-ideal competitive adsorption in Donnan-like gels (NICA-Donnan model) in a proof of concept study. The NICA-Donnan approach allows for the development of a set of model parameters that are independent of ionic strength and $\mathrm{pH}$, and thus calculation of metal speciation can be undertaken at ambient sample $\mathrm{pH}$ or the $\mathrm{pH}$ of a future, more acidic ocean. There is currently a lack of basic NICA-Donnan parameters applicable to marine dissolved organic matter (DOM) so we assumed that the measured marine dissolved organic carbon could be characterized as terrestrial fulvic acids. Generic NICA-Donnan parameters were applied within the framework of the software program visual MINTEQ and the metal-added ligand concentrations [MeAL] calculated for the AdCSV-CLE conditions. For copper, calculated [MeAL] using the NICA-Donnan model for DOM were consistent with measured [MeAL], but for iron an inert fraction with kinetically inhibited dissolution was required in addition to the NICA-Donnan model in order to approximate the trends observed in measured [MeAL]. We calculated iron and copper speciation in Northwest European shelf water samples at ambient alkalinity and projected increased $\mathrm{pCO}_{2}$ concentrations as a demonstration of the potential of the approach.

Keywords: trace metals, speciation, pH, iron solubility, NICA-Donnan, CLE-AdCSV 


\section{INTRODUCTION}

The increase in atmospheric $\mathrm{CO}_{2}$ concentrations over the past two centuries has led to an enhanced $\mathrm{CO}_{2}$ uptake by the oceans (Feely et al., 2004). This uptake has lowered the surface ocean $\mathrm{pH}$ (Caldeira and Wickett, 2003), and changed the balance of the carbonate species (Doney, 2006), leading to a decrease in the carbonate ion concentration $\left(\mathrm{CO}_{3}^{-2}\right)$ and an increase in aqueous $\mathrm{CO}_{2}$ and bicarbonate concentrations (Zeebe and WolfGladrow, 2001; Orr et al., 2005). The increase in atmospheric partial pressure of $\mathrm{CO}_{2}\left(p \mathrm{CO}_{2}\right)$ from preindustrial $(\sim 280 \mu \mathrm{atm})$ to current levels $(\sim 400 \mu \mathrm{atm})$ has already caused a reduction of ca. $0.1 \mathrm{pH}$ units (Caldeira and Wickett, 2003; Feely et al., 2004). If anthropogenic $\mathrm{CO}_{2}$ emissions and ocean $\mathrm{CO}_{2}$ uptake continues along current trends, a decrease in $\mathrm{pH}$ of about $0.3-$ 0.5 units by the year 2100 in the surface oceans is possible (Brewer, 1997; Zeebe and Wolf-Gladrow, 2001; Feely et al., 2004; Orr et al., 2005; Doney, 2006). Carbonate ion concentrations are expected to drop by half over this century, making it more difficult for marine calcifying organisms to form biogenic calcium carbonate $\left(\mathrm{CaCO}_{3}\right)$, and to maintain their external skeletons (Orr et al., 2005). These changes in ocean chemistry could have strong impacts on marine ecosystems, even under future scenarios in which most of the remaining fossil fuel derived $\mathrm{CO}_{2}$ is not released (Kleypas et al., 1999; Riebesell et al., 2000; Caldeira and Wickett, 2003; Langdon et al., 2003).

Changes in ocean $\mathrm{pH}$ and carbonate chemistry could also have significant impacts on the chemical speciation of essential trace elements in seawater (Millero et al., 2009; Shi et al., 2010; Gledhill et al., 2015). In the surface ocean, trace metals that have a significant biological role for oceanic phytoplankton are manganese, iron, cobalt, copper, zinc, and cadmium (Morel and Price, 2003). Iron is an essential micronutrient involved in fundamental cellular processes, including respiration, photosynthesis, nitrogen uptake and nitrogen fixation (Geider and La Roche, 1994; Raven et al., 1999; Hogle et al., 2014). Iron controls productivity, species composition and trophic structure of microbial communities in large regions of the ocean (Sunda and Huntsman, 1995a; Johnson et al., 1997; Hunter and Boyd, 2007). Iron concentrations in oceanic waters are very low due to its low solubility and effective removal from the surface ocean by phytoplankton (Liu and Millero, 2002). Organic complexation is thought to maintain dissolved iron concentrations above its inorganic solubility (Liu and Millero, 2002), whilst potentially reducing the concentrations of the soluble, bioavailable inorganic species (Shaked and Lis, 2012). It has been demonstrated that iron deficiency limits phytoplankton growth in High Nitrate Low Chlorophyll (HNLC) waters such as the equatorial and subarctic Pacific, Southern Ocean, and coastal upwelling regions (Martin and Fitzwater, 1988; Boye et al., 2005; Boyd et al., 2007). Furthermore, in nutrient poor, low latitude waters iron helps to regulate nitrogen fixation (Moore et al., 2009). As a consequence, iron strongly influences oceanic $\mathrm{CO}_{2}$ drawdown in these regions (De Baar et al., 2008). A decrease in seawater $\mathrm{pH}$ from 8.1 to 7.4, which would correspond to an increase in $p \mathrm{CO}_{2}$ to approximately $1800 \mu \mathrm{atm}$, will increase the solubility of $\mathrm{Fe}(\mathrm{III})$ by about $40 \%$, which could have a large impact on biogeochemical cycles (Morel and Price, 2003; Millero et al., 2009). A decrease in $\mathrm{pH}$ has also been suggested to result in higher iron availability to phytoplankton, as a result of enhanced proton competition for the available iron-binding ligand places (Raven et al., 2005; Millero et al., 2009). A recent estuarine study suggested that concentrations of inorganic, bioavailable iron would increase 3 fold with a pH reduction from 8.18 to 7.41 (Gledhill et al., 2015), but that concentrations of dissolved organic carbon (DOC) could play an overriding role in determining iron speciation. The acidbase chemistry of the DOC binding sites is thus likely to be of key importance to any changes in iron speciation under future climate change scenarios (Shi et al., 2010).

Copper is an essential micronutrient for marine phytoplankton. It is involved in iron uptake (Peers et al., 2005), and in the ocean's nitrogen cycle (Jacquot et al., 2013). Limitation of phytoplankton growth has also been observed in laboratory phytoplankton strains at free copper ion concentrations of less than $10^{-15} \mathrm{M}$ (Sunda and Huntsman, 1995b; Annett et al., 2008; Guo et al., 2012). $\mathrm{Cu}(\mathrm{II})$ is also toxic and free copper (II) ion concentrations as low as $10^{-12} \mathrm{M}$ have been shown to reduce growth in marine phytoplankton (Brand et al., 1986) resulting in a relatively narrow optimal growth range. Complexation of copper by organic ligands can decrease its toxicity by decreasing the free cupric ion concentration (Moffett and Brand, 1996; Moffett et al., 1997; Croot et al., 2000). A pH decrease may reduce copper binding by both organic ligands and carbonate, therefore making copper more bioavailable and consequently toxic to marine phytoplankton. It has been predicted that the increase for the free form of copper $\left(\mathrm{Cu}^{2+}\right)$ under a scenario where $\mathrm{pH}$ is reduced to 7.5 , will be as high as $30 \%$ (Millero et al., 2009) whilst Gledhill et al. (2015) found that $\mathrm{Cu}^{2+}$ concentrations could increase in estuaries by an order of magnitude under a similar scenario of $\mathrm{pH}$ reduction to 7.4, if DOC concentrations remained the same. Such increases could thus result in a higher potential for copper toxicity in coastal and estuarine ecosystems.

There are only a few studies that have considered the effect of ocean acidification on the speciation and/or bioavailability of trace metals to marine organisms (Turner et al., 1981; Byrne et al., 1988; Byrne, 2002; Millero et al., 2009; Shi et al., 2010; Gledhill et al., 2015). Here we extend our recent investigations (Gledhill et al., 2015) into the impact of decreasing $\mathrm{pH}$ on the complexation of iron and copper at reduced $\mathrm{pH}$ to waters of the Northwest European shelf seas. The aim of this study was to experimentally determine changes in the speciation of iron and copper that might result from an increase in $p \mathrm{CO}_{2}$ and a consequent decrease in surface ocean $\mathrm{pH}$. We therefore carried out competitive ligand equilibrium (CLE) titrations using adsorptive cathodic stripping voltammetry as a detection method (AdCSV) on 20 samples collected from Northwest European shelf seas at $\mathrm{pH}$ 7.91, 7.37, and 6.99 (expressed on the total $\mathrm{pH}$ scale). We used salcylaldoxime $\left(\mathrm{H}_{2} \mathrm{SA}\right)$ as the competing ligand for copper, and 1-nitroso-2-napthol (HNN) as the competing ligand for iron. Competitive ligand equilibrium titrations are generally interpreted as analogous to adsorption isotherms (Ruzic, 1982; Gerringa et al., 1995). Adsorption isotherms can be interpreted using a number of different models (Foo and Hameed, 2010). In this study we used two different methods that have previously 
been applied to marine waters to interpret our data (Gerringa et al., 1995; Hiemstra and Van Riemsdijk, 2006). Firstly we treated the natural metal complexing ligands $\left(\mathrm{L}_{i}\right)$ as discrete ligands and utilized the Langmuir isotherm to obtain conditional stability constants $\left(K_{M e L, M e^{\prime}}^{\text {cond }}\right)$ and ligand concentrations $\left[\mathrm{L}_{i}\right]$ for each sample (Gerringa et al., 1995, 2014). Secondly we used the NICA-Donnan model, which considers dissolved organic matter (DOM) to be heterogeneous and non-ideal, and subject to multicomponent competition and electrostatic interactions (Koopal et al., 2005) and thus we considered DOM to contain a continuous distribution of binding sites analogous to complex organic compounds like fulvic acids (Laglera et al., 2007; Laglera and Van Den Berg, 2009; Batchelli et al., 2010; Hassler et al., 2011; Whitby and Van Den Berg, 2015). For the NICA-Donnan approach we compared calculated and measured concentrations of metal-added ligand complexes, given the determined DOC concentrations (Gledhill et al., 2015). The utility of the NICADonnan approach was then demonstrated through calculation of the speciation of iron and copper in our coastal water samples at the natural $\mathrm{pH}$ and total alkalinity of the samples observed during the cruise (Ribas-Ribas et al., 2014) and at 280, 900 and $1900 \mu$ atm $p \mathrm{CO}_{2}$ (approximately $2 \times$ and $5 \times 2014$ values), assuming total alkalinity and DOC remain unchanged.

\section{MATERIALS AND METHODS}

\section{Sample Collection}

Seawater samples were collected in Northwest European shelf seas (Figure 1, Table S1) during the RRS Discovery 366 cruise in June and July 2011. Surface seawater (ca. 2-3 m deep) was collected daily from a towed fish and was filtered in-line inside a clean container through a $0.2 \mu \mathrm{m}$ pore size filter capsule (Sartobran P-300, Sartorious). The seawater was stored in $250 \mathrm{ml}$ low density polyethylene bottles ( $250 \mathrm{~mL}$ LDPE; Nalgene) for the subsequent determination of iron and copper speciation. Bottles were pre-cleaned according to a standard protocol described by Achterberg et al. (2001) and just prior to sampling were rinsed thoroughly with deionised water (MilliQ, Millipore; $>18.2 \mathrm{~m} \Omega$ $\mathrm{cm}$ ) and then with seawater. Samples for copper-binding ligand analysis were stored at $4{ }^{\circ} \mathrm{C}$ for subsequent analysis on board the ship (within 1 day). Samples for the determination of iron speciation were frozen immediately after collection $\left(-20^{\circ} \mathrm{C}\right)$ and analyzed in a clean laboratory at the National Oceanography Centre, Southampton. Samples for the determination of total dissolved trace metals were collected using $60 \mathrm{ml}$ LDPE bottles (Nalgene), acidified to $\mathrm{pH} 1.8(0.011 \mathrm{M}$ final concentration) using ultraclean $\mathrm{HCl}$ (Romil UpA grade) and stored at room temperature.

\section{Determination of $\mathrm{pH}$ and Dissolved Organic Carbon}

The $\mathrm{pH}$ of the original seawater sample was determined on the total $\mathrm{pH}$ scale $\left(\mathrm{pH}_{\text {total }}\right)$ using an automated $\mathrm{pH}$ system (Rérolle et al., 2012) connected to the ship's underway water supply, which collected water at a depth of $\sim 5 \mathrm{~m}$. $\mathrm{pH}$ was determined using spectrophotometry with Thymol Blue as the pH indicator (Clayton and Byrne, 1993; Rérolle et al., 2012). The

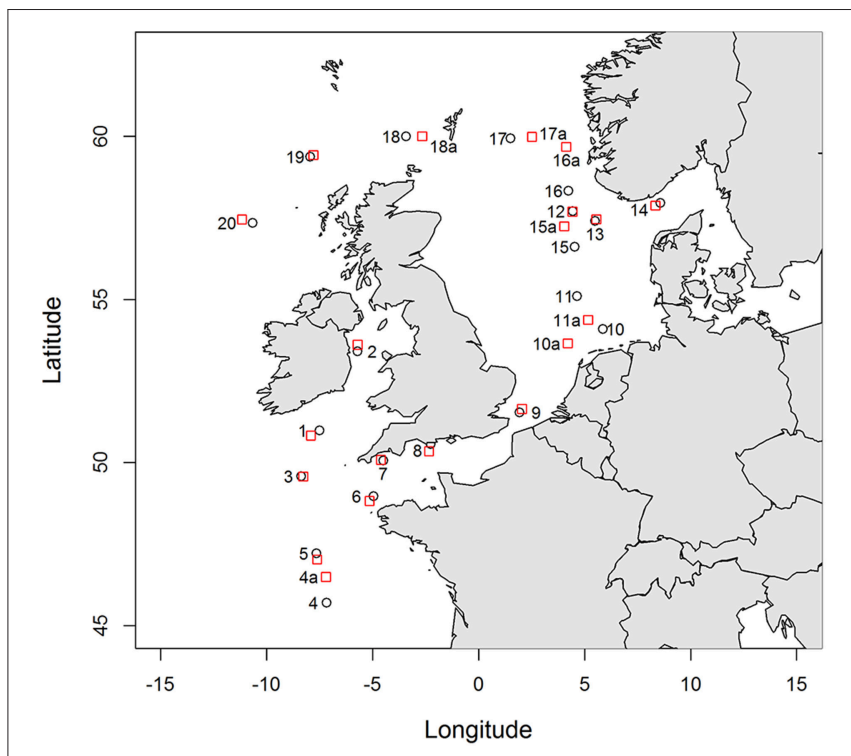

FIGURE 1 | Locations sampled from the CTD cast (red squares) and from the underway sampling system (black circles). Where stations are not directly adjacent, underway samples are labeled with the station number and the letter $a$. spectrophotometric method had a precision of $1 \mathrm{mpH}$ units and measured $\mathrm{pH}$ values were within $0.004 \mathrm{pH}$ units of certified Tris $\mathrm{pH}$ buffer (Scripps Institute of Oceanography, University of San Diego).

The $\mathrm{pH}$ of buffer solutions used during titrations was determined on the IUPAC scale ( $\mathrm{pH}_{\mathrm{NBS}}$ ). Although, the IUPAC scale is not optimal for seawater, stability constants describing metal complexation are determined on this scale and so it was considered appropriate for this study. $\mathrm{pH}$ was determined on titration aliquots immediately post analysis using a Metrohm $\mathrm{pH}$ meter. For comparative purposes, buffered seawater (in the absence of any added ligands) was also measured with the spectrophotometric technique (Rérolle et al., 2012), and respective values obtained on the total $\mathrm{pH}$ scale $\left(\mathrm{pH}_{\text {total }}\right)$, which were: $6.99 \pm 0.01$ for $\mathrm{pH}_{\mathrm{NBS}} 7.2,7.37 \pm 0.005$ for $\mathrm{pH}_{\mathrm{NBS}} 7.6$, and $7.91 \pm 0.005$ for $\mathrm{pH}_{\mathrm{NBS}}$ 8.05. $\mathrm{pH}_{\mathrm{NBS}}$ was thus $0.21 \pm 0.03 \mathrm{pH}$ units higher than $\mathrm{pH}_{\text {total }}$ at $20^{\circ} \mathrm{C}$ (Gledhill et al., 2015).

Dissolved organic carbon was determined on samples collected from the stainless steel CTD rosette (Macgilchrist et al., 2014). For our study we used results from the sample collected from CTD stations positioned closest to our underway sample obtained at a depth between 2 and $9 \mathrm{~m}$. Samples were filtered through precombusted $\left(450^{\circ} \mathrm{C}, 4 \mathrm{~h}\right)$ glass fiber filters $(0.7 \mu \mathrm{m}$ nominal cutoff; MF300, Fisher Scientific) into precombusted glass ampoules and immediately acidified to $\mathrm{pH} 2$ with $5 \mathrm{M} \mathrm{HCl}$. The ampoules were flame sealed, stored at room temperature and analyzed on shore by high temperature catalytic combustion (Badr et al., 2003). We obtained a value of $41.8 \pm 0.9 \mu \mathrm{M} \mathrm{C}(n=$ 15) for acidified deep seawater reference material provided by $D$. Hansell (University of Miami) against a certified concentration range of 41-43 $\mu \mathrm{M} \mathrm{C}$. 


\section{Determination of Total Dissolved Iron and Copper Concentrations}

Total dissolved metal concentrations were determined by inductively coupled plasma-mass spectrometry (ICP-MS) on acidified $\left(\mathrm{pH}_{\mathrm{NBS}} 1.8\right)$ samples after a salt removal and off-line pre-concentration/matrix removal step using a Toyopearl AF$650 \mathrm{M}$ chelating column (Milne et al., 2010). Briefly, $12 \mathrm{ml}$ of the acidified sample in an acid cleaned $30 \mathrm{ml}$ FEP bottle (Nalgene) was spiked with a multi-element standard of isotopes (containing the stable isotopes ${ }^{65} \mathrm{Cu}$, and ${ }^{57} \mathrm{Fe}$ ) with known enrichments over their natural abundance. The spiked samples were left for overnight equilibration. Subsequently, the samples were buffered to $\mathrm{pH} 6.4 \pm 0.2$ using $2 \mathrm{M}$ ammonium acetate, prepared with ultrapure acetic acid and ammonia (Fisher Optima).

The buffered sample was then pumped over the preconcentration column, at $2 \mathrm{ml} \mathrm{min}{ }^{-1}$. The column was rinsed with $1 \mathrm{ml}$ de-ionized water to remove salts, and subsequently the metals were eluted for $30 \mathrm{~s}$ using $1 \mathrm{ml}$ of $1 \mathrm{M}$ distilled $\mathrm{HNO}_{3}$ (Savilex). The eluent was collected into acid cleaned autosampler polypropylene vials (OmniVials; $4 \mathrm{ml}$ ) and capped.

The extracted samples were analyzed using a high resolutionICP-MS (Element XR, Thermofisher). The sample was introduced via a $100 \mu \mathrm{l}$ Teflon nebuliser connected to a PFA spray chamber. Measurements for iron, and copper were performed in medium resolution mode $(R=4000)$. The detection limit was determined to be 0.033 and $0.054 \mathrm{nmol} \mathrm{L}^{-1}$ for iron and copper, respectively, and blank values were typically $0.06 \mathrm{nmol} \mathrm{L^{-1 }}$ for iron and $0.02 \mathrm{nmol} \mathrm{L}^{-1}$ for copper. Values determined for the SAFe surface reference sample were within the consensus range $\left(0.09 \pm 0.03 \mathrm{nmol} \mathrm{L}^{-1}\right.$ for iron, and $0.55 \pm$ $0.06 \mathrm{nmol} \mathrm{L}^{-1}$ for copper).

\section{Determination of Iron and Copper Speciation Via Competitive Ligand Exchange with Detection by Adsorptive Cathodic Stripping Voltammetry (CLE)}

Determination of the iron and copper speciation in seawater was performed via measurement of the quantity of each metal $(\mathrm{Me})$ that is available to complex with an added ligand (AL) using CLE-AdCSV, with 1-nitroso-2-naphthol (HNN) for iron (Yokoi and Van Den Berg, 1992; Gledhill and Van Den Berg, 1994; Van Den Berg, 1995), and salicylaldoxime $\left(\mathrm{H}_{2} \mathrm{SA}\right)$ for copper (Campos and van den Berg, 1994) as the competing ligands.

The electrochemical system consisted of a potentiostat ( $\mu$ Autolab Ecochemie, Netherlands) with a static mercury drop electrode (Metrohm, 663 VA stand), a $\mathrm{KCl}$ reference electrode $(\mathrm{Ag} / \mathrm{AgCl}$ in $3 \mathrm{M} \mathrm{KCl}$ saturated with $\mathrm{AgCl})$ and a counter electrode of glassy carbon. Two systems were used in parallel on board ship for the analysis of copper speciation, and one system in the laboratory for the analysis of iron speciation.

All chemicals were prepared in a clean electrochemistry laboratory under a Class 100 laminar flow bench at room temperature $\left(20^{\circ} \mathrm{C}\right)$. A stock solution of $0.01 \mathrm{M} \mathrm{HNN}$ (Sigma) was prepared in methanol (Fisher, HPLC grade). A stock solution of $0.01 \mathrm{M} \mathrm{H}_{2} \mathrm{SA}$ (Sigma) was prepared in $0.1 \mathrm{M} \mathrm{HCl}$ (Romil, $\mathrm{SpA}$ grade). Standard $\mathrm{Fe}(\mathrm{III})$ and $\mathrm{Cu}(\mathrm{II})$ solutions of $10^{-6} \mathrm{M}$ for additions were prepared using a $1000 \mathrm{mg} / \mathrm{L}$ ICP-MS stock solution (Fisher Scientific), and were acidified to $\mathrm{pH} 2$ using $\mathrm{HCl}$ (Romil, SpA grade).

Stock solutions of $1 \mathrm{M}$ N-2-hydroxyethylpiperazine-N'ethanesulphonic acid (HEPES; Fisher Aristar grade) $\mathrm{pH}$ buffer were prepared in $0.35,0.6$, and $0.9 \mathrm{M}$ ammonia (Romil, SpA grade) in order to provide a $\mathrm{pH}$ of $7.2,7.6$, and 8.05 upon 100 -fold dilution with sea water. HEPES was cleaned prior to use by the addition of HNN with subsequent removal of HNN and $\mathrm{Fe}(\mathrm{NN})_{3}$ using a previously activated $\mathrm{C}_{18}$ SepPak column (Whatman).

For the ship-board determination of copper speciation, the $\mathrm{pH}$ was adjusted in three individual $250 \mathrm{ml}$ LDPE bottles to 8.05, 7.6, and 7.2 through addition of $\mathrm{pH}$ adjusted $1 \mathrm{M}$ HEPES buffers (0.01 M final concentration) immediately after collection, and with a $0.01 \mathrm{M}$ solution of the competing ligand $\mathrm{H}_{2} \mathrm{SA}(10 \mu \mathrm{M}$ final concentration). The samples were subsequently equilibrated for a minimum period of $1 \mathrm{~h}$ at room temperature $\left(\sim 20^{\circ} \mathrm{C}\right)$. An aliquot of $15 \mathrm{ml}$ of the sample solution was then pipetted into $30 \mathrm{ml}$ polystyrene cups. A copper (II) standard solution was spiked to give an added concentration range between 0 and $30 \mathrm{nM}$ in 14 steps. The copper and ligands in the sample aliquots were allowed to equilibrate overnight $(>12 \mathrm{~h})$ at room temperature.

The concentration of $\mathrm{Cu}(\mathrm{HSA})_{2}$ in the samples was determined using the following procedure: (i) removal of oxygen from the samples for $5 \mathrm{~min}$ with nitrogen gas (oxygen free grade), after which 5 fresh $\mathrm{Hg}$ drops were formed, (ii) a deposition potential of $-0.1 \mathrm{~V}$ was applied for $60 \mathrm{~s}$ whilst the solution was stirred to facilitate the adsorption of the $\mathrm{Cu}(\mathrm{HSA})_{2}$ to the $\mathrm{Hg}$ drop, and (iii) at the end of the adsorption period, the stirrer was stopped and the potential was scanned from -0.1 to $-0.4 \mathrm{~V}$ using the square wave method at a frequency of $100 \mathrm{~Hz}$. The stripping current (peak height) from the reduction of the adsorbed $\mathrm{Cu}(\mathrm{HSA})_{2}$ complex was recorded. The $\mathrm{pH}$ on each of the titration steps was checked after each measurement and found to agree with the $\mathrm{pH}$ prior to measurement.

Iron speciation was determined in a clean laboratory under a Class 100 laminar flow bench, in Southampton. The frozen samples for the iron speciation measurements were thawed prior to analysis to reach room temperature, and then buffered using the same procedure as for the copper samples. In the case of the iron titrations, an added ligand concentration of $1 \mu \mathrm{M}$ $\mathrm{NN}$ was used, with the exception of the $\mathrm{pH} 8.05$ experiment $(2 \mu \mathrm{M} N N)$. Added iron concentrations ranged between 0 and $8 \mathrm{nM}$ in 14 steps, pipetted into $30 \mathrm{ml}$ polytetrafluoroethene (PTFE) vessels. Samples were left to equilibrate for $16 \mathrm{~h}$ (overnight).

The concentration of $\mathrm{FeNN}_{3}$ was determined after de-aeration of the sample with nitrogen gas $(5 \mathrm{~min})$. A deposition potential at $-0.1 \mathrm{~V}$ was used with a deposition time of $3 \mathrm{~min}$; the scanning mode was sample-DC from $-0.15 \mathrm{~V}$ to $-0.65 \mathrm{~V}$ at a scan rate of $50 \mathrm{mV} \mathrm{s}^{-1}$, the reduction peak of iron appeared at approximately $-0.45 \mathrm{~V}$. 


\section{Data Treatment Applied to Competitive Ligand Exchange Titrations}

Addition of a competing or added ligand to natural seawater results in the establishment of a new equilibrium between the free metal $\left(M e^{n+}\right)$, inorganic metal complexes $\left(M e^{\prime}\right)$, natural organic complexing material (NOCM) and the $A L$.

$$
\begin{aligned}
M e^{n+}+M e^{\prime}+ & M e(N O C M)+x A L \leftrightarrow M e^{n+}+M e^{\prime} \\
& +M e(N O C M)+M e A L_{x}
\end{aligned}
$$

The approach assumes that the concentration of the competing AL species is in excess of the binding sites in the NOCM, and works optimally when the binding sites in NOCM are in excess of the metal concentration in the sample. Addition to the sample of further free metal $\left(M e^{n+}\right)$ in increasing increments, accompanied by determination of the concentration of $M e A L_{x}$ and calculation of $M e^{\prime}$ and $M e^{n+}$ using known equilibrium constants allows for the estimation of the concentration of $M e(N O C M)$ at each titration point in the experiment. Modeling the relative changes in all four components of the equilibrium allows for the relative concentration and strength of the NOCM binding sites to be established. In this study we used two approaches to model changes in metal speciation during the titration: (1) the single window discrete ligand approach and (2) the NICA-Donnan model. The first approach allowed us to obtain conditional stability constants $K_{\mathrm{MeL}_{i}}^{\mathrm{cond}}$ and the maximum concentration of metal that could bind to NOCM in each sample at the three $\mathrm{pH}$ levels at which the samples were analyzed. The second approach was used to calculate the speciation of iron and copper independent of $\mathrm{pH}, \mathrm{CO}_{2}$, and DOC concentrations and thus allowed for examination of the impact of future increases in $p \mathrm{CO}_{2}$ to be investigated in North West European shelf sea waters.

Results of CLE-AdCSV are highly dependent on the method used to define the sensitivity of the electrochemical response (Pizeta et al., 2015). In this study we used the internal method, which calculates $M e A L_{x}$ concentrations from the slope of the saturated part of the titration curve, normally the last three to five titration points. Average slopes observed at the three different $\mathrm{pHs}$ in this study are given in Table 1. Although slopes were variable between samples, we observed no systematic difference in slope with DOC (results not shown) for either iron or copper. Copper titrations were performed at sea on two separate instruments made up of the same components. A large difference in slope (ca. $2.3 \times$ ) was observed between the two instruments employed for copper titrations.

\section{The Single Detection Window Discrete Ligand Approach}

In the single detection window discrete ligand approach (hereafter referred to simply as the discrete ligand approach), NOCM is considered to consist of classes of discrete ligands $\left(L_{i}\right)$ which vary in strength. The strongest ligand class is termed $L_{1}$ and progressively weaker ligands $L_{2}, L_{3}$ etc. Importantly in this approach, the stoichiometry between $M e$ and $L_{i}$ is assumed to be 1:1 (Pizeta et al., 2015). This approach has been used extensively for describing metal complexation in marine systems and considerable effort has been directed toward determining
TABLE 1 | Average slopes observed for the last three titration points at different titration $\mathrm{pHs}$.

\begin{tabular}{lcc}
\hline $\mathbf{p H}_{\mathbf{N B S}}$ & \multicolumn{2}{c}{ Slope $\left(\mathbf{n A ~ n m o l}{ }^{-1}\right)$} \\
\cline { 2 - 3 } & $\mathrm{FeNN}_{\mathbf{3}}$ & $\boldsymbol{\Sigma} \mathbf{C u}(\mathbf{H S A})_{\boldsymbol{X}}$ \\
\hline 8.0 & $0.83 \pm 0.09$ & $2.1 \pm 0.5 ; 4.5 \pm 0.2$ \\
7.6 & $0.95 \pm 0.61$ & $1.9 \pm 0.6 ; 4.8 \pm 0.6$ \\
7.2 & $0.84 \pm 0.22$ & $2.1 \pm 0.8 ; 4.9 \pm 0.7$ \\
\hline
\end{tabular}

Slopes are given separately for the two instruments used for copper titrations.

different ligand classes (e.g., Sander et al., 2011) in the hope of properly representing the full range of metal complexes likely to be present in the marine environment. In our study we undertook titrations at different $\mathrm{pH}$ for each sample, applying one added ligand concentration for each metal. The theoretical considerations for the determination of natural ligand binding characteristics assuming discrete ligands has been described in detail for iron and HNN by Gledhill and Van Den Berg (1994); Van Den Berg (1995), and in the case of $\mathrm{Cu}$ with $\mathrm{H}_{2} \mathrm{SA}$ by Campos and van den Berg (1994). The overall mass balance, conditional stability constants for $M e A L_{x}$ and the sensitivity of the voltammetric response are used to determine concentrations of $M e^{\prime}$ and $M e L_{i}$ for each titration point. Values for $M e^{\prime}$ and $M e L_{i}$ are then used to calculate the conditional stability $K_{M e L_{i}}^{c o n d}$ and ligand concentration $\left[L_{i}\right]$ of the metal ligand complex using the equation

$$
\left[M e L_{i}\right]=\frac{K_{M e L_{i}}^{c o n d}\left[L_{i}\right]\left[M e^{\prime}\right]}{\left(1+K_{M e L_{i}}^{c o n d}\left[M e^{\prime}\right]\right)}
$$

where $K_{M e L_{i}}^{\text {cond }}$ is the conditional stability constant for metal complexation with the natural ligand $\left(L_{i}\right)$. Equation (1) is equivalent to the Langmuir isotherm and $K_{M e L_{i}}^{\text {cond }}$ and $\left[L_{i}\right]$ were calculated using non-linear regression (Gerringa et al., 1995) and a script in the computer program $\mathrm{R}$ (Gerringa et al., 2014). The coefficients and constants used in the discrete ligand approach in this study are listed in Table 2. Although the discrete ligand approach has been extensively used to describe metal complexation in the marine environment, a limitation of this approach is that the conditional stability constants and ligand concentrations are, by definition, conditional and thus specific to the ionic strength, $\mathrm{pH}$ and temperature of the sample at the time it was analyzed.

\section{Modeling Iron and Copper Complexation by Dissolved Organic Matter with the Non-Ideal Competitive Adsorption-Donnan Approach}

The NICA-Donnan approach is one of a suite of modeling approaches (Dudal and Gérard, 2004; Tipping, 2005; Stockdale et al., 2015; Tipping et al., 2015) that attempts to represent the complexity of metal complexation with DOM in a way which is independent of $\mathrm{pH}$, ionic strength and the presence of competing cations. In the NICA-Donnan model, DOM is considered to behave like humic or fulvic acids (Kinniburgh et al., 1996; Koopal et al., 2005). The NICA-Donnan model accounts for both the 
TABLE 2 | Conditional stability constants for added ligands and inorganic side reaction coefficients for iron and copper used in this study.

\begin{tabular}{|c|c|c|c|c|c|}
\hline $\mathrm{pH}_{\mathrm{NBS}}$ & $\underset{\mathrm{log} \mathrm{K}_{\mathrm{Fe}(\mathrm{NN})_{3}, \mathrm{Fe}^{3+}}^{\text {cond }}}{{ }^{3+}}$ & $\log _{C u H S A, C u^{2+}}^{c o n d}$ & ${ }^{\log \beta_{\mathrm{Cu}(\mathrm{HSA})_{2}, \mathrm{Cu}}^{\text {cond }}}$ & $\log \alpha_{F e^{\prime}}$ & ${ }^{\log \alpha}{ }_{C u^{\prime}}$ \\
\hline 8.0 & 29.3 & 8.4 & 14.0 & 9.8 & 0.89 \\
\hline 7.6 & 29.3 & 8.0 & 13.2 & 8.8 & 0.27 \\
\hline 7.2 & 29.2 & 7.7 & 12.4 & 8.1 & -0.09 \\
\hline
\end{tabular}

chemical (NICA) and electrostatic (Donnan) affinity of binding sites. In the NICA component, the overall equation used to obtain the fraction of total number of binding sites $\left(\theta_{I, \text { max }}\right)$ occupied by the $i$ th component (e.g., proton, iron, copper) at concentration $C_{i}$ is

$$
\theta_{i, \max }=\frac{\left(K_{i} \cdot C_{i}\right)^{n_{i}}}{\sum_{i}\left(K_{i} \cdot C_{i}\right)^{n_{i}}} \cdot \frac{\left\{\sum_{i}\left(K_{i} \cdot C_{i}\right)^{n_{i}}\right\}^{p}}{1+\left\{\sum_{i}\left(K_{i} \cdot C_{i}\right)^{n_{i}}\right\}^{p}}
$$

where the NICA constant $\left(K_{i}\right)$ describes the mean binding affinity for the $i$ th component, $n_{i}$ is the non-ideality constant, and $p$ is width of the binding site distribution (Koopal et al., 2005). The overall density of binding sites $\left(Q_{\max , T}\right)$ is assumed to be equivalent to the density of proton binding sites $\left(Q_{\operatorname{maxH}, T}\right)$. Proton affinities $\left(\mathrm{K}_{H}\right)$ are considered to occur in a continuous Sips bimodal affinity distribution that is thought to encompass two groups of binding sites-a low proton affinity (acidic) group and a high proton affinity (basic) group of sites (Koopal et al., 2005). The following normalization condition is thus used to give thermodynamic consistency to the NICA isotherm and calculate of the amount $\left(Q_{i, \max }\right)$ of component $i$, bound by DOM, where $n_{H}$ is the non-ideality constant for the binding of protons

$$
Q_{i, \max }=Q_{\max , T} \theta_{i, \max }\left(\frac{n_{i}}{n_{H}}\right)
$$

Substituting Equation (3) in Equation (4) the following general expression describing the binding of metal, $\mathrm{Me}(\mathrm{Cu}$ or $\mathrm{Fe})$ by marine DOM (Milne et al., 2003)

$$
\begin{aligned}
Q_{M e}= & Q_{\max 1, T} \frac{n_{M e, 1}}{n_{H 1}} \cdot \frac{\left(K_{M e, 1} \cdot C_{M e}\right)^{n_{M, 1}}}{\left(K_{H, 1} \cdot C_{H}\right)^{n_{H, 1}}+\left(K_{M e, 1} \cdot C_{M e}\right)^{n_{M e, 1}}} . \\
& \frac{\left\{\left(K_{H, 1} \cdot C_{H}\right)^{n_{H, 1}}+\left(K_{M e, 1} \cdot C_{M e}\right)^{n_{M e, 1}}\right\}^{p 1}}{1+\left\{\left(K_{H, 1} \cdot C_{H}\right)^{n_{H, 1}}+\left(K_{M e, 1} \cdot C_{M e}\right)^{n_{M e, 1}}\right\}^{p 1}} \\
+ & Q_{\max 2, T} \frac{n_{M e, 2}}{n_{H 2}} \cdot \frac{\left(K_{M e, 2} \cdot C_{M e}\right)^{n_{M e, 2}}}{\left(K_{H, 2} \cdot C_{H}\right)^{n_{H, 2}}+\left(K_{M e, 2} \cdot C_{M e}\right)^{n_{M e, 2}}} \\
& \cdot \frac{\left\{\left(K_{H, 2} \cdot C_{H}\right)^{n_{H, 2}}+\left(K_{M e, 2} \cdot C_{M e}\right)^{n_{M e, 2}}\right\}^{p 2}}{1+\left\{\left(K_{H, 2} \cdot C_{H}\right)^{n_{H, 2}}+\left(K_{M e, 2} \cdot C_{M e}\right)^{n_{M e, 2}}\right\}^{p 2}}
\end{aligned}
$$

where $Q_{\max 1, T}, Q_{\max 2, T}$ refer to the total number of type 1 and type 2 proton binding sites respectively.

The NICA approach is combined with the Donnan model in order to account for electrostatic interactions that occur in gel like substances. The Donnan model relates the molecular charge $\sigma$ of a natural organic molecule to its Donnan volume $V_{D}$ and electrostatic potential $\psi$.

$$
\sigma=V_{D} \sum_{i} z_{i} C_{0, i} e^{\frac{-z_{i} F \psi}{R T}}
$$

where $z_{i}$ is the valence of the $i$ th component, $C_{0, i}$ is the concentration of $i$ th component in solution, $\mathrm{F}$ is the Faraday constant, $\mathrm{R}$ the gas constant and $\mathrm{T}$ the absolute temperature (K). The Donnan volume is related to ionic strength through the empirical formula (Benedetti et al., 1996)

$$
\log V_{D}=0.57(1-\log I)-1
$$

The combined NICA-Donnan model was applied to our dataset using the computer program visual MINTEQ v 3.0 (vMINTEQ; Gustafsson, 2012). vMINTEQ incorporates the NICA-Donnan model into a calculation of the speciation of inorganic and simple organic molecules (such as ethylenediaminetetraacetic acid, EDTA) or ions at thermodynamic equilibrium. vMINTEQ uses stability constants from the NIST database (Martell and Smith, 2004) for inorganic and simple organic complexes. The salinity of each sample was used to derive the molality of the major ions $\mathrm{Na}^{+}, \mathrm{K}^{+}, \mathrm{Ca}^{2+}, \mathrm{Mg}^{2+}, \mathrm{Sr}^{2+}, \mathrm{Cl}^{-}, \mathrm{SO}_{4}^{2-}, \mathrm{Br}^{-}, \mathrm{BO}_{3}^{3+}$, and $\mathrm{F}^{-}$for a temperature of $20^{\circ} \mathrm{C}$ and a density of $1025 \mathrm{~kg}$ $\mathrm{m}^{-3}$. The inorganic/simple organic part of the algorithm has not been optimized for modeling at ionic strengths as high as seawater. We used the extended Davies equation to correct for ionic interactions, but many components lack the DebyeHückel constants required to properly extend the calculations into the ionic strength range of seawater. Comparison of calculated speciation for the carbonate system (Gledhill et al., 2015) with that produced by $\mathrm{CO}_{2}$ SYS, a speciation model specifically designed for seawater (Pierrot et al., 2006), resulted in underestimation of $\left[\mathrm{CO}_{3}^{2-}\right]$, a factor which is likely related to the ionic strength algorithm employed in vMINTEQ (Gledhill et al., 2015). Here, as in our previous study, we therefore forced the total $\left[\mathrm{CO}_{3}^{2-}\right]$ concentration to agree with the total $\left[\mathrm{CO}_{3}^{2-}\right]$ concentration produced by $\mathrm{CO}_{2} \mathrm{SYS}$ by multiplying total inorganic carbon $\left(\mathrm{T}_{c}\right)$ by 1.2 in order to compensate for the underestimation of total $\left[\mathrm{CO}_{3}^{2-}\right]$ and improve the calculation of inorganic copper species across our $\mathrm{pH}$ range. Forcing $\left[\mathrm{CO}_{3}^{2-}\right]$ concentrations resulted in $82.0 \pm 0.4 \%$ and $68.2 \pm 0.8 \%(n=$ 20) of inorganic copper being present as carbonate species in our samples at $\mathrm{pH} 8.1$ and 7.6 respectively, which is of similar magnitude to that calculated by Millero et al. (2009).

For the NICA-Donnan model, we considered DOC in our samples to consist entirely of fulvic acids. We applied the 
generic parameters for total binding sites $Q_{\operatorname{maxH}, T}$, binding site distribution $(p)$, the NICA constant $(K)$ and non-ideality constant $\left(n_{H}\right)$ for type 1 (acidic) and 2 (basic) sites to describe FA proton binding, and NICA constants and non-ideality constants for complexation of FA by the major competing ions calcium, magnesium and strontium. The generic parameter set for the NICA-Donnan model has been derived from $\mathrm{pH}$ or metal titration experiments on soil and freshwater fulvic fractions (Milne et al., 2003). The Donnan equation, which accounts for the effects of ionic strength, has been established using a relatively limited dataset (Benedetti et al., 1996), albeit one that extends up to an ionic strength of 1 . Similar characterization of marine DOM has yet to be undertaken and is challenging because of the difficulties of isolating and preconcentrating sufficient DOM to carry out such experiments. For NICADonnan modeling of iron and copper complexation with fulvic acid, we first used two parameter sets based on more recent studies (see Table 3 ) in marine waters. The presence of an inert iron fraction (Gledhill and Buck, 2012) was accounted for by first calculating iron solubility in our samples using the sample DOC concentration, the relevant NICA-Donnan parameters and ferrihydrite precipitation with the solubility constant derived by Liu and Millero (1999) at the $\mathrm{pH}$ of the original seawater sample (i.e., not the $\mathrm{pH}$ of the titration). An additional equation was added in order to consider the presence of an inert fraction at saturated concentrations of $\mathrm{Fe}^{\prime}$ that did not react with $\mathrm{NN}$ within the timescale of our titration

$$
\mathrm{Fe}^{3+}+\mathrm{Fe}^{\prime}+\mathrm{NOCM} \leftrightarrow \mathrm{Fe}^{3+}+\mathrm{Fe}^{\prime}+\mathrm{Fe}(\mathrm{NOCM})+\mathrm{Fe}_{\text {inert }}
$$

Once $F e_{\text {inert }}$ was calculated and subtracted from the $\mathrm{dFe}$ concentration, then the equilibrium between $\mathrm{NN}$ and $\mathrm{Fe}^{3+}, \mathrm{Fe}^{\prime}$, and $\mathrm{Fe}(\mathrm{NOCM})$ was calculated with vMINTEQ. Salicylaldoxime and HNN were added as ligands to vMINTEQ. Protonation constants for the added ligands were taken from the NIST critical stability constant database (Table 3; Martell and Smith, 2004). Stability constants for vMINTEQ for complexation of copper with $\mathrm{HSA}^{-}$, and iron with $\mathrm{NN}^{-}$were empirically derived from titrations of added ligands with EDTA and, for SA, from titrations in UV-irradiated seawater varying the $\mathrm{H}_{2} \mathrm{SA}$ concentration (Gledhill et al., 2015). The derived stability constants are conditional to the ionic strength and major ion composition of seawater and valid for the $\mathrm{pH}$ range used in our study. Concentrations of $M e A L_{x}$ were calculated in vMINTEQ at the $\mathrm{pH}$ and $\left[\mathrm{CO}_{3}^{2-}\right]$ concentrations of the experimental titration $\mathrm{pH}$. Calculated concentrations of $M e A L_{x}$ were compared to measured concentrations of $M e A L_{x}$ in order to empirically minimize the root mean squared error. We then used the best parameter set to calculate iron and copper speciation in our samples at the observed $\mathrm{pH}_{\mathrm{NBS}}$ and $1.2 \times \mathrm{T}_{c}$ calculated by $\mathrm{CO}_{2} \mathrm{SYS}$ from measured total alkalinity and $p \mathrm{CO}_{2}$ values of $280,400,900$, and $1900 \mu \mathrm{atm}$. Calculations were carried out at $20^{\circ} \mathrm{C}$ as this was the temperature at which titrations were performed and there is little information with respect to how NICA-Donnan complexation in seawater will change with temperature.

The updated thermodynamic database, components database, and the NICA-Donnan databases used in this study are provided as Data sheet 1 in Supplementary Material. Because of the limitations resulting from the mechanism used to correct for ionic strength and the lack of knowledge with respect to the complexation properties of marine DOC, these databases should be used with caution and the results presented here should thus be regarded in the context of "proof of concept," rather than a fully accurate interpretation of iron and copper speciation in these waters. Nevertheless, useful information can be obtained from applying this approach to marine systems with respect to the general behavior of complex DOM over the $\mathrm{pH}$ range of our study.

\section{RESULTS}

\section{Salinity, Sea Surface Temperature $\left(\mathrm{SST}^{\circ} \mathrm{C}\right)$ and Surface pH}

The hydrography of the cruise has been discussed in more detail by Poulton et al. (2014). Salinity varied between 31.3 and 35.8 at the 20 sampling stations, except in the Skagerrak area where a salinity of 27.4 was observed (Figure 2A). Sea surface temperature (SST) varied between 11.2 and $17.1^{\circ} \mathrm{C}$, with the lowest value observed at station 2 in the Irish Sea and the highest at station 14 in the Skagerrak area.

The concentrations of DOC ranged between 61 and $145 \mu \mathrm{mol}$ $\mathrm{L}^{-1}$ (Figure 2B), with the maximum value observed at station 14 in the Skagerrak area. The high DOC concentration observed in the surface waters $(<5 \mathrm{~m})$ at this station was associated with a surface extrusion of high temperature, low salinity waters that originated from the Baltic Sea or the coastal waters of Sweden. Similar high DOC values $\left(>100 \mu \mathrm{mol} \mathrm{L}^{-1}\right)$ were also observed at $<5 \mathrm{~m}$ in the adjacent two CTD stations (Macgilchrist et al., 2014).

Surface seawater $\mathrm{pH}_{\text {Total }}$ at the 20 sampling stations varied from 8.04 to 8.23 (Figure 2C), with the highest values observed at station 18 in the northern North Sea and station 19 in the Atlantic sector of the cruise, which had some of the lowest temperature values observed during the cruise, and featured enhanced chlorophyll concentrations (up to $1.6 \mu \mathrm{gL}^{-1}$ Poulton et al., 2014). Lowest $\mathrm{pH}$ values were observed at station 8 in the English Channel and at the southern North Sea stations (10, 11, 15).

Total dissolved iron $(\mathrm{dFe})$ concentrations varied between 0.5 and $5.4 \mathrm{nM}$ (Figure 3A), with an average of $2.2 \pm 1.5 \mathrm{nM}$ except in the southern North Sea (station 10) and the Skagerrak area (station 14), where dFe concentrations were high (21.0 and $10.6 \mathrm{nM}$, respectively). Total dissolved copper (dCu) concentrations varied between 0.4 and $5.1 \mathrm{nM}$ (Figure 3B), with an average of $2.3 \pm 1.3 \mathrm{nM}$.

\section{Organic and Copper Binding Ligand Characteristics in the Northwest European Shelf Seas - the Effect of Acidification}

The enhanced concentrations of $\mathrm{dFe}$ and $\mathrm{dCu}$ typically observed in the shelf sea waters resulted in natural ligand pools that were close to saturation, if not saturated, for many of our titrations. As such fitting the discrete ligand model was problematic for many of our samples as was also reported for deep ocean 
TABLE 3 | Constants used for NICA-Donnan modeling.

\begin{tabular}{|c|c|c|c|c|c|}
\hline & \multicolumn{2}{|c|}{ Iron } & \multicolumn{2}{|c|}{ Copper } & Added ligand \\
\hline$A^{a}$ & $\begin{array}{l}\log K=3.6 \\
n=0.3\end{array}$ & $\begin{array}{l}\log K=11.2 \\
n=0.15\end{array}$ & $\begin{array}{l}\log K=0.26 \\
n=0.63\end{array}$ & $\begin{array}{l}\log K=7.26 \\
n=0.36\end{array}$ & $\begin{array}{l}\mathrm{Fe}\left(\mathrm{NN}_{3}\right)_{3}, \log \mathrm{K}=32.5 \\
\mathrm{pKa}_{H N N}=7.9^{\mathrm{C}}\end{array}$ \\
\hline $\mathrm{B}^{\mathrm{b}}$ & $\begin{array}{l}\log K=2.8 \\
n=0.36\end{array}$ & $\begin{array}{l}\log K=8.3 \\
n=0.23\end{array}$ & $\begin{array}{l}\log K=0.26 \\
n=0.63\end{array}$ & $\begin{array}{l}\log K=8.26 \\
n=0.36\end{array}$ & $\begin{array}{l}\mathrm{Cu}(\mathrm{HSA})^{+}, \log \mathrm{K}=18^{\mathrm{C}} \\
\mathrm{Cu}(\mathrm{HSA})_{2}, \log \mathrm{K}=41.1\end{array}$ \\
\hline
\end{tabular}

a Gledhill et al., 2015.

b Hiemstra and Van Riemsdijk, 2006.

c Martell and Smith, 2004.

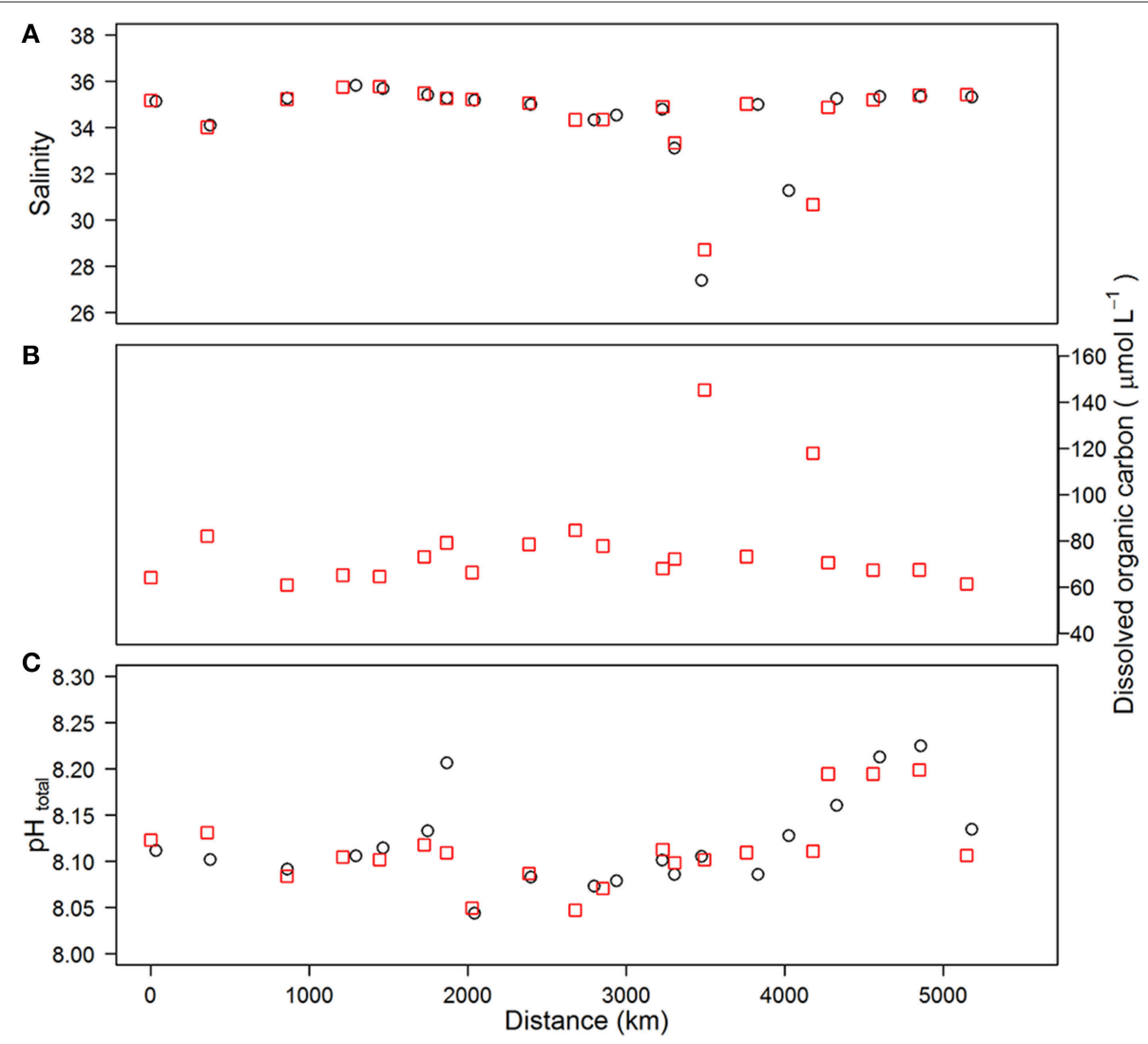

FIGURE 2 | Salinity (A), dissolved organic carbon (B) and pH (C) obtained for CTD samples (red squares) and underway samples (black circles) plotted as a function of distance along the cruise track.

hydrothermal samples (Hawkes et al., 2013). Results are only presented for titrations that produced a significant fit for log $K_{M e L_{i}, M e^{\prime}}^{\text {cond }}$ and $L_{i, M e}$ at the $90 \%$ confidence level (i.e., $p<0.1$ ). Thus, 13 out of 30 titrations were successfully fitted to the discrete ligand model for iron, whilst 16 out of 30 fits were successful for copper. In order to examine the potential cause for the fit failing, we assessed the impact of random error on a simulated titration similar to that observed for station 1 . We randomly generated 2,5 , and $10 \%$ error on each titration point for 10 simulated titrations and then analyzed the resultant simulated titrations with the non-linear discrete ligand model. Our analysis, indicated that a random error of as little as $2 \%$ on each titration point would result in poor fits $(p>0.1)$ for the discrete ligand model in two out of five simulations using our metal addition regime, a random error of $5 \%$ resulted in $p>0.1$ for $60 \%$ of the fits and a random error of $10 \%$ resulted in complete failure (i.e., no successful fits) of the discrete model approach. 


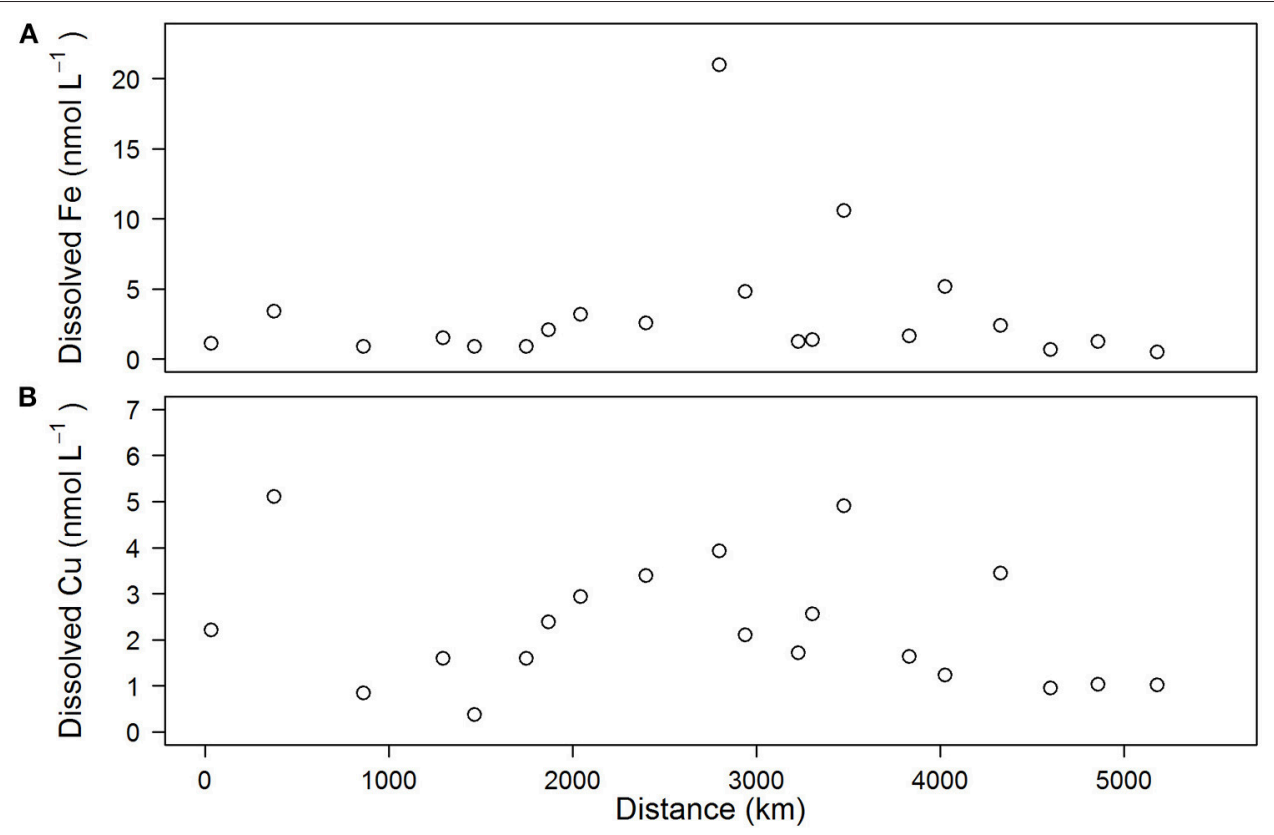

FIGURE 3 | Concentrations of dissolved iron (A) and dissolved copper (B) observed in underway samples plotted as a function of distance along the cruise track.

\section{Iron and Copper Binding Ligands $\left[\mathrm{L}_{\mathrm{i}, \mathrm{Fe}}\right],\left[\mathrm{L}_{\mathrm{i}, \mathrm{Cu}}\right]$ and Stability Constants}

Metal binding ligand concentrations $\left[L_{i, M e}\right]$ determined using our detection windows in the surface waters of the Northwest European shelf seas for the range of $\mathrm{pH}_{\mathrm{NBS}}$ 8.05-7.2 are given in Table S2 and shown in Figure 4. Iron binding ligand concentrations $\left[L_{i, F e}\right]$ at $\mathrm{pH}_{\mathrm{NBS}} 8.05$ averaged of $4.7 \pm 2.0 \mathrm{nM}$ $(n=7)$. At $\mathrm{pH}_{\mathrm{NBS}} 7.6,\left[L_{i, F e}\right]$ averaged $4.0 \pm 0.8 \mathrm{nM}(n=2)$, and at $\mathrm{pH} 7.2,\left[L_{i, F e}\right]$ averaged $2.6 \pm 0.8 \mathrm{nM}(n=3)$, excluding station 10 , where a value of $22.6 \mathrm{nM}$ was observed. There was no apparent trend of $\left[L_{i, F e}\right]$ with $\mathrm{pH}$.

Copper-binding ligand concentrations $\left[L_{i, C u}\right]$ at $\mathrm{pH}_{\mathrm{NBS}} 8.05$ averaged $3.4 \pm 1.3 \mathrm{nM}(n=3)$. At pH 7.6, $\left[L_{i, C u}\right]$ averaged $6.0 \pm$ $3.3 \mathrm{nM}(n=7)$, and at $\mathrm{pH}_{\mathrm{NBS}} 7.2,\left[L_{i, C u}\right]$ averaged $6.0 \pm 3.6 \mathrm{nM}$ $(n=6)$. As in the case of iron, there was no trend in $\left[L_{i, C u}\right]$ with the decline of $\mathrm{pH}_{\mathrm{NBS}}$ from 8.05 to 7.2 (Figure 4B). Results for $\log$ $K_{F e L_{i}, F e^{\prime}}^{c o n d}$ obtained in this study are shown in Figure 4C, Table S2. $\log K_{\mathrm{FeL}_{i}, \mathrm{Fe}^{\prime}}^{\text {cond }}$ increased with decreasing $\mathrm{pH}$, from approximately 11.2 at $\mathrm{pH}_{\mathrm{NBS}} 8.05$, to 11.7 at $\mathrm{pH}_{\mathrm{NBS}} 7.6$ and 13.1 at $\mathrm{pH}_{\mathrm{NBS}} 7.2$. In contrast $\log K_{C u L_{i}, C u^{\prime}}^{\text {cond }}$ did not show a trend with a decrease in $\mathrm{pH}$ (Figure 4D, Table S2).

\section{NICA-Donnan Modeling of Iron and Copper Complexation}

\section{Selection of NICA-Donnan parameters}

The addition of HNN and $\mathrm{H}_{2} \mathrm{SA}$ to vMINTEQ allowed the concentrations of $\mathrm{FeNN}_{3}$ and $\Sigma \mathrm{Cu}(\mathrm{HSA})_{x}$ to be calculated as a function of NICA-Donnan binding by DOC. Our study region covered a wide range of dissolved iron concentrations, with particularly elevated concentrations in the North Sea, as also observed previously (Gledhill et al., 1998). At such high iron concentrations, it is likely that some of the iron measured as dissolved iron, would be present in an inert, potentially colloidal fraction (Gledhill and Buck, 2012; Hawkes et al., 2013; Von Der Heyden and Roychoudhury, 2015). Figure 5 shows the impact of accounting for the presence of an inert phase that is in selective disequilibrium with $\mathrm{HNN}$, for three titrations on samples 3,10, and 14, which were determined to have very different $\mathrm{dFe}$ concentrations $(0.9,21$, and 10.6 respectively). Our titration data showed that measured $\mathrm{FeNN}_{3}$ did not depend greatly on the concentration of $\mathrm{dFe}$ originally present in the sample, as illustrated in Figure 5A. These results suggest that only a fraction of the iron was actually in equilibrium with HNN (Gledhill and Buck, 2012). Calculating $\left[\mathrm{FeNN}_{3}\right]$ concentrations with the assumption that all $\mathrm{dFe}$ was in equilibrium with $\mathrm{HNN}$, results in increased $\mathrm{FeNN}_{3}$ when $\mathrm{dFe}$ concentrations are higher as observed in Figure 5B. However, when an inert fraction is calculated according to Equation (8), prior to calculating the equilibrium between the added ligand, $\mathrm{Fe}^{3+}, \mathrm{Fe}^{\prime}$, and $\mathrm{Fe}(\mathrm{NOCM})$ then we obtained a pattern more representative of our observations (Figure 5C). We used insoluble ferrihydrite as our inert fraction in this study, as increasing the strength of complexation parameters describing NOCM in an attempt to create an "inert" Fe fraction bound to NOCM resulted in a similar trend to Figure $5 \mathrm{~B}$, albeit with lower calculated $\mathrm{FeNN}_{3}$ concentrations. Our observations could thus only be described by incorporation of a solid phase with kinetically inhibited dissolution into our model.

Plots of calculated $M e A L_{x}$ vs measured $M e A L_{x}$ produced after incorporation of an inert iron fraction using three different parameter sets are shown in Figure 6. We adopted an empirical 

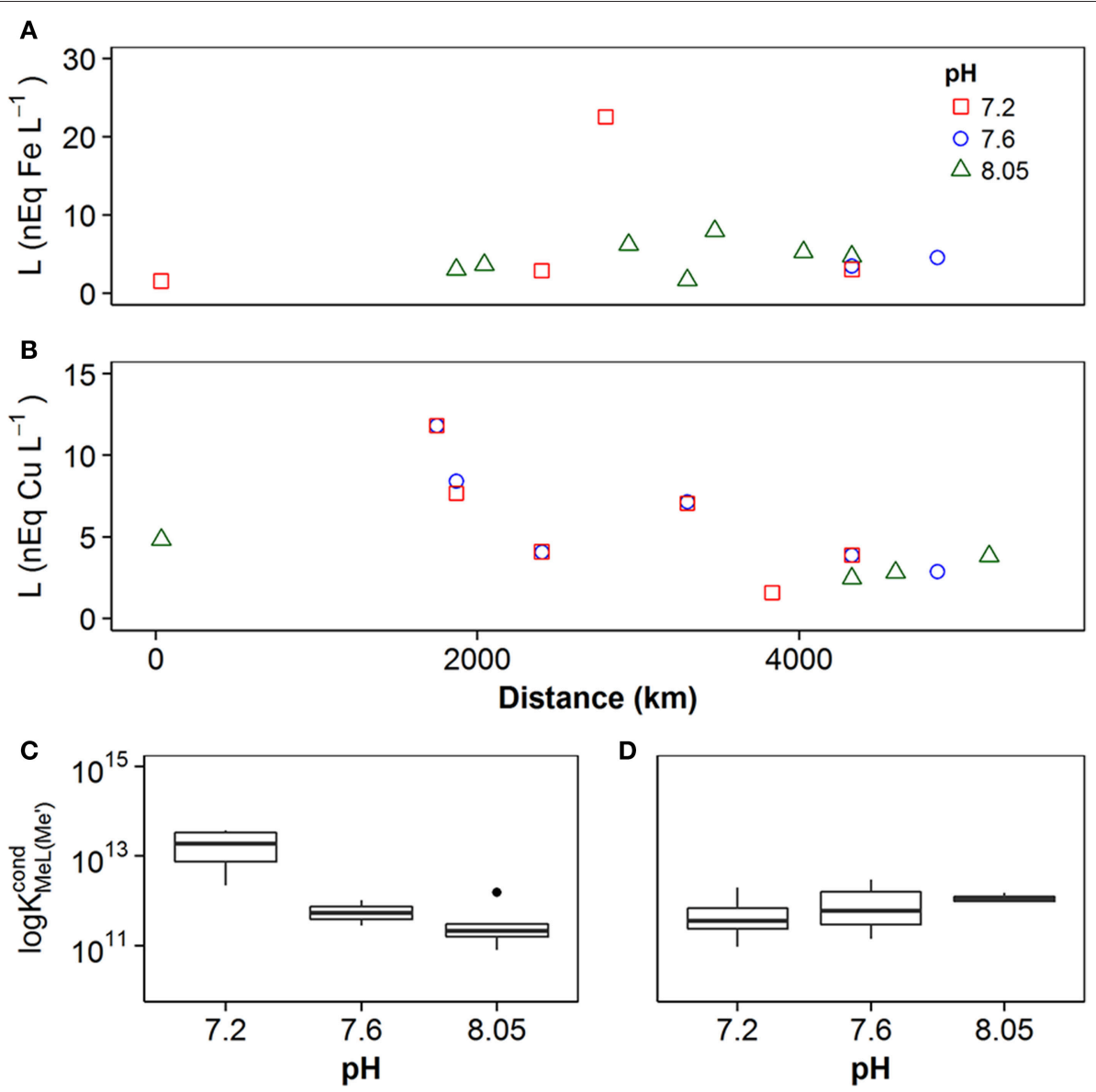

FIGURE 4 | Concentrations of ligand estimated in samples using the discrete ligand approach for (A) iron and (B) copper. Error bars represent \pm 1 standard deviation from the average. (C) Box and whisker plots obtained for conditional stability constants $\mathrm{K}_{\mathrm{Fe} L_{i}, \mathrm{Fe}^{\prime}}$ observed at pH 8.0, 7.6, and 7.2 for iron (C) and copper (D). The box incorporates the 25th and 75th percentiles, whilst outliers are plotted as black circles.

approach to model optimization, as this was a proof of concept study. Root mean squared errors obtained from comparison of measured vs. calculated data at each $\mathrm{pH}$ are presented in Table 4. For iron, parameters derived for our previous estuarine study (A) and by Hiemstra and Van Riemsdijk (2006) (B) resulted in an overestimation of $\mathrm{FeNN}_{3}$ at lower $\mathrm{pH}$ values, although those derived by Hiemstra and Van Riemsdijk (2006) resulted in an improved fit as observed from lower RMSE (Table 4). Increasing the apparent strength of the more acidic fraction (FA1) by both reducing the non-ideality factor for FA1 to 0.26 and increasing the NICA constant to 3.6 improved the fit at lower pH (Figure 6C, Table 4). It should be noted here that we assumed the inert iron fraction was also inert to the change in temperature as it is commonly assumed that there is no impact on titration data from freezing (Buck et al., 2012). We assumed the inert fraction was also inert to the change in $\mathrm{pH}$ on the timescale of our titrations (< day) as incorporating ferrihydrite precipitation at the $\mathrm{pH}$ of the titration resulted in an increased RMSE for iron at $\mathrm{pH} 7.6$ and $\mathrm{pH} 7.8$ (results not shown) and thus a $\mathrm{pH}$ trend inconsistent with observed results. For copper, parameters derived for our estuarine study (A) resulted in a better approximation of $\Sigma \mathrm{Cu}(\mathrm{HSA})_{x}$ with no $\mathrm{pH}$ bias in RMSE, although $\Sigma \mathrm{Cu}(\mathrm{HSA})_{x}$ was consistently underestimated (Figure 6). Set A was, however, an improvement on the generic parameters (Milne et al., 2003; Set B, Table 3) and a further decrease in $\log \mathrm{K}_{F A 2(C u)}$ and $n_{F A 2 C u}$ resulted in an improved fit of the calculated to the measured $\Sigma \mathrm{Cu}(\mathrm{HSA})_{x}$ concentrations (Figure 6C).

In order to understand the potential impact of the different NICA-Donnan model parameters on conditional stability constants and ligand concentrations, we applied the discrete model approach to the simulated titration datasets. Results from the calculation of stability constants and ligand concentrations from the simulated titrations are shown in Figure 7. We compared $\left[L_{i, M e}\right]$ determined from our titrations $\left(\mathrm{L}_{\text {measured }}\right)$ with the apparent $\left[L_{i, M e}\right]$ determined from the simulated titrations ( $\mathrm{L}_{\text {NICA-Donnan }}$ ) (Figures 7A,B), and we plotted the average of the conditional stability constants for each $\mathrm{pH}$ and for the three different model parameter sets in Figures 7C,D. For iron, log $K_{\mathrm{FeL}_{i}, \mathrm{Fe}^{\prime}}^{\mathrm{cond}}$ and $L_{i, \mathrm{Fe}}$ obtained from simulated data agreed quite 

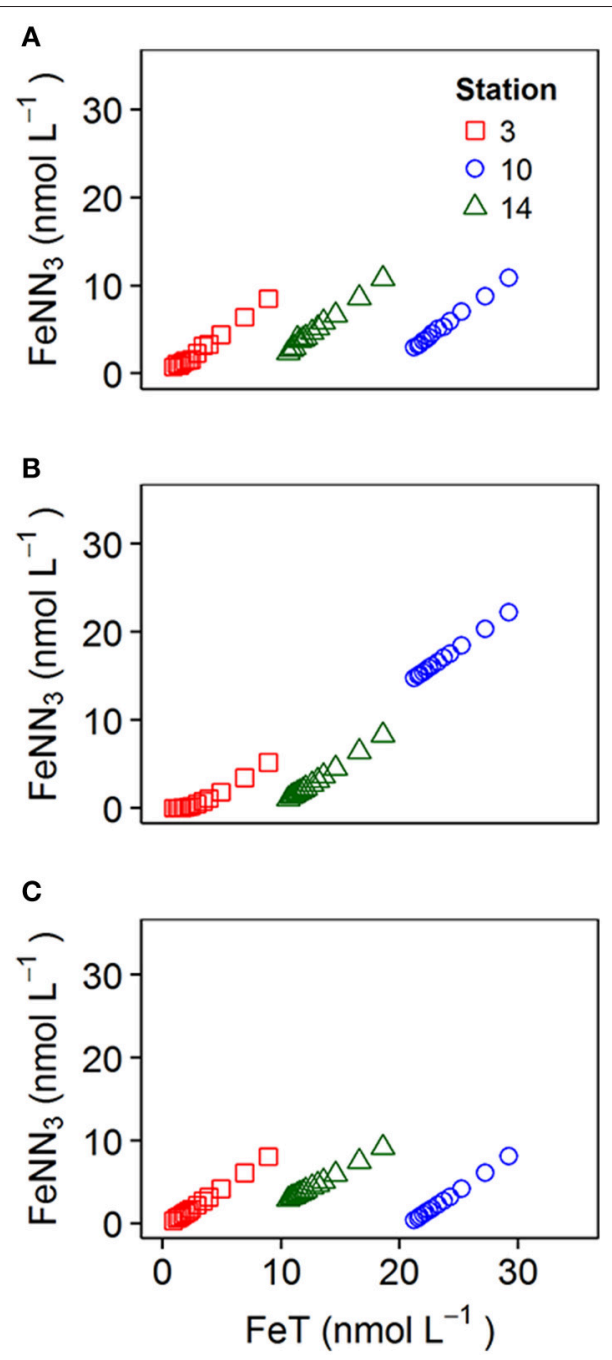

FIGURE 5 | Iron competitive ligand equilibrium titrations at pH 8.0 (A) observed for station 3,10 , and 14, (B) simulated using dissolved organic matter calculated with NICA-Donnan parameters only considering organic complexation and $(\mathrm{C})$ simulated using NICA-Donnan parameters and incorporating an insoluble inert iron phase represented by ferrihydrite.

well with that obtained from the real titrations. Correlation coefficients between $\mathrm{L}_{\text {NICA-Donnan }}$ and $\mathrm{L}_{\text {measured }}$ were $>0.95$ for all three parameter sets for iron. For copper, $\log K_{\mathrm{CuL}}^{c o n d}, \mathrm{Cu}$ obtained for the simulated titrations were within the range of those obtained for real samples (Figure 7D), but ligand concentrations did not agree well for any of the applied parameter sets (Figure 7B).

\section{Application of the NICA-Donnan Model to the Prediction of the Impact of Increasing $\mathrm{pCO}_{2}$ on Iron and Copper Complexation}

Increasing $p \mathrm{CO}_{2}$ from 280 to 400,900 , and $1900 \mu$ atm resulted in decreases in $\mathrm{pH}$ of $0.13,0.45$, and $0.75 \mathrm{pH}$ units respectively, while the concentration of carbonate ions decreased to 78,42 , and
TABLE 4 | RMSE (nmol L-1) obtained on comparison of measured $M e A L_{x}$ concentrations with calculated $M e A L_{X}$ concentrations obtained using vMINTEQ.

\begin{tabular}{lccc}
\hline Parameter Set & pH & Iron & Copper \\
\hline A & 8.05 & 1.2 & 3.88 \\
& 7.6 & 1.9 & 3.55 \\
& 7.2 & 1.8 & 3.55 \\
B & 8.05 & 0.9 & 7.2 \\
& 7.6 & 1.0 & 6.8 \\
& 7.2 & 1.2 & 6.7 \\
C & 8.05 & 1.1 & 2.1 \\
& 7.6 & 1.0 & 2.4 \\
& 7.2 & 0.7 & 2.4 \\
\hline
\end{tabular}

$22 \%$ of preindustrial levels respectively. The projected changes in these inorganic major ions would thus be expected to have an impact on both iron and copper speciation. Results obtained from calculation of the speciation of iron and copper in our shelf sea samples at decreased $\mathrm{pH}$ and $\mathrm{CO}_{3}^{2-}$ ion concentrations are presented in Figures 8, 9. Figure 8 shows the proportion of metal bound to fulvic acid analogs ("Bound"), the inert fraction ("Inert"-for iron only) and present as simple inorganic ion pairs or as the free metal ("Inorganic"), while Figure 9 shows the changes in inorganic iron $\left(\mathrm{pFe}^{\prime}\right)$ and free $\mathrm{Cu}^{2+}\left(\mathrm{pCu}^{2+}\right)$ in more detail. Iron was present mainly in the bound fraction, with the inert fraction becoming important at iron concentrations greater than ca. 4-5 nM, (depending on the concentration of DOC) at $p \mathrm{CO}_{2}<400 \mu \mathrm{atm}$. When modeled as inorganic ferric hydroxides, the inert fraction was reduced by increases in $p \mathrm{CO}_{2}$, so that at $p \mathrm{CO}_{2}$ levels of $1900 \mu \mathrm{atm}$, bound iron reached concentrations as high as ca. $10.9 \mathrm{nM}$ at Station 10. In this study, we observed that the concentration of the biologically available inorganic iron decreased (i.e., pFe' increased since it is the negative log of the inorganic iron concentration, Figure 9A) with increasing $p \mathrm{CO}_{2}$. However, this trend was reversed when iron concentrations were high enough to result in the formation of an inert fraction (i.e., when the solubility of $\mathrm{Fe}^{\prime}$ was exceeded, and ferrihydrite was formed).

Copper was predominantly present bound to DOM (71-95\%, Figure 8). Free $\mathrm{Cu}^{2+}$ concentrations were calculated to vary between ca. $10^{-12}$ and $10^{-10} \mathrm{nM}$, with increasing $p \mathrm{CO}_{2}$ resulting in increased free $\mathrm{Cu}^{2+}$ concentrations (Figure 9B), as reported previously (Gledhill et al., 2015).

\section{DISCUSSION}

In this study we have undertaken the most comprehensive investigation to date into changes in the speciation of the trace metals iron and copper that result from changes in $\mathrm{pH}$. We interpreted measurements of metal speciation using CLE-AdCSV with the discrete ligand approach and a NICA-Donnan modeling approach. We applied two data interpretation approaches in this study, but there are further approaches that have been applied to trace metal complexation in the marine environment including 

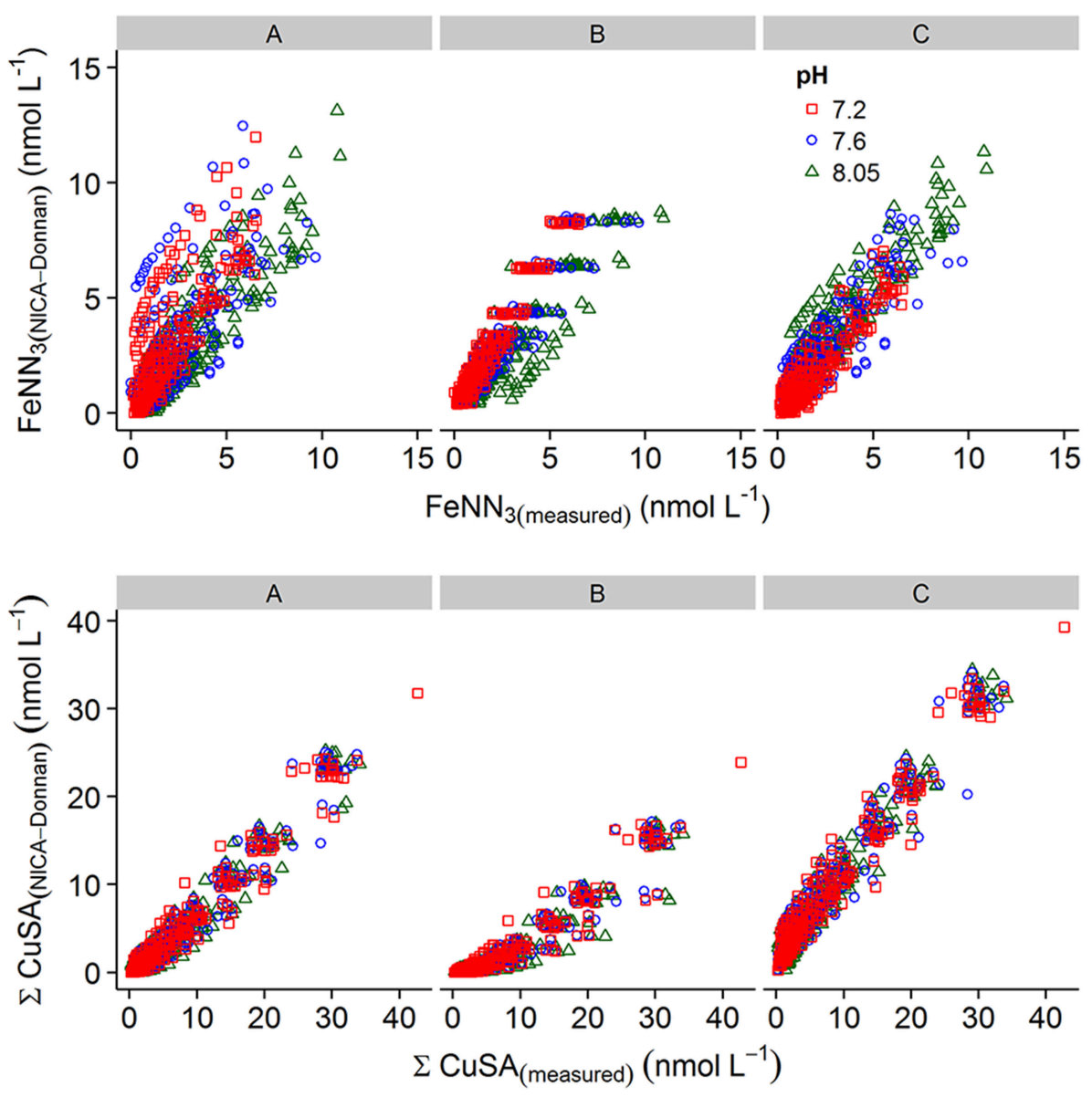

FIGURE 6 | Plots of measured versus calculated metal added ligand concentrations obtained using parameter sets (A-C) applied to the NICA-Donnan model in vMINTEQ. Top panel, iron; bottom panel, Cu. The applied parameter set is given above the graph. For details of the parameter sets, see Table $\mathbf{3}$.

those described in Pizeta et al. (2015), WHAM VII (Stockdale et al., 2011, 2015) and the Stockholm Humic Model (Gustafsson, 2001; Ndungu, 2012). In our discussion, we will first examine the changes in $\log K_{M e L_{i}, M e^{\prime}}^{c o n d}$ and $L_{i, M e}$ concentrations with $\mathrm{pH}$ obtained with the discrete ligand approach. We then assess the potential of the NICA-Donnan model as an alternative method for the interpretation of CLE titrations. Finally, we illustrate the potential utility of the NICA-Donnan approach through an investigation of the potential effects of an increase in $\mathrm{pCO}_{2}$ on the iron and copper speciation in our shelf sea samples.

\section{The Single Detection Window Discrete Ligand Approach}

The discrete ligand approach allowed us to identify an increase in conditional stabilities for iron natural ligand complexes of the order of $1.9 \log$ units with a decrease in $\mathrm{pH}$ from 8.05 to 7.2 (Figure 4), similar to that observed previously by Gledhill et al. (2015) who observed an increase of $2 \log$ units with a decrease in $\mathrm{pH}$ from 8.3 to 6.8. This increase in $\log K_{F e L_{i}, F e^{\prime}}^{c o n}$ with a decrease in $\mathrm{pH}$ provides further evidence for the dependence of iron binding on the $\mathrm{pH}$ of seawater and suggests that in a more acidic ocean, ligand strengths are likely to increase relative to the strength of inorganic complexation, largely as a result of decreases in the concentration of hydroxide ions. Although the relative trend with $\mathrm{pH}$ was similar to previous observations, conditional stabilities for iron detected in this study were slightly stronger than those observed in the previous estuarine study, especially at lower $\mathrm{pH}$. This could relate to real changes in binding site characteristics as DOM is transported offshore and aged. On the other hand, the experimental results on which the estuarine model was based were acknowledged to be less reliable below pH 8 as the detection window was not optimal (Gledhill et al., 2015). In this study, we adjusted the concentration of the added ligand HNN (from $2 \mu \mathrm{mol} \mathrm{L}{ }^{-1}$ used in Gledhill et al. (2015) to $1 \mu \mathrm{mol} \mathrm{L}^{-1}$ in this study) in order to lower our detection window and thereby improve the reliability of estimates obtained with the discrete ligand approach at lower $\mathrm{pH}$. The increase in the conditional stabilities observed at low $\mathrm{pH}$ could thus be related to a reduction in systematic errors associated with fitting the discrete ligand model resulting from improved detection window selection. Nevertheless, it was a notable feature of our study that 


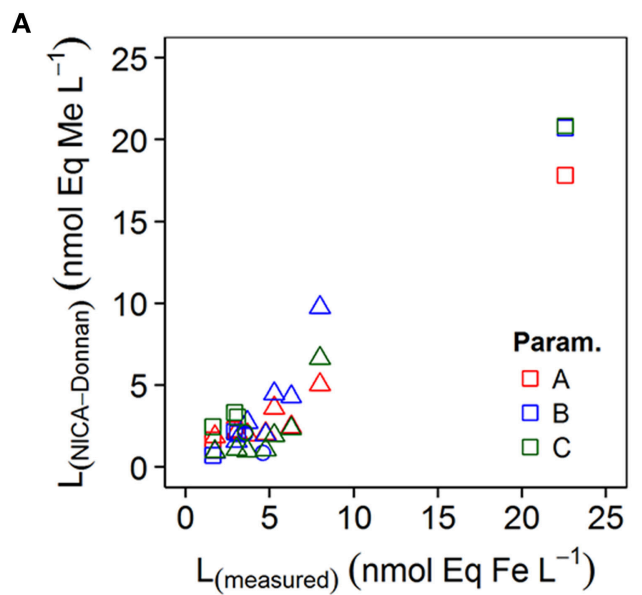

C

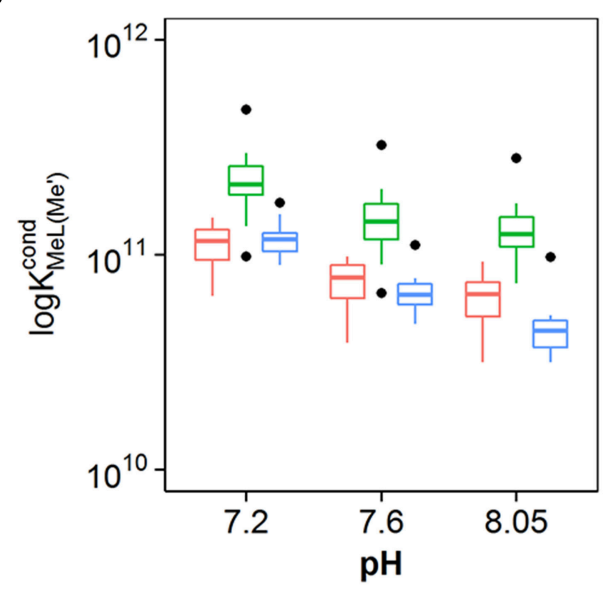

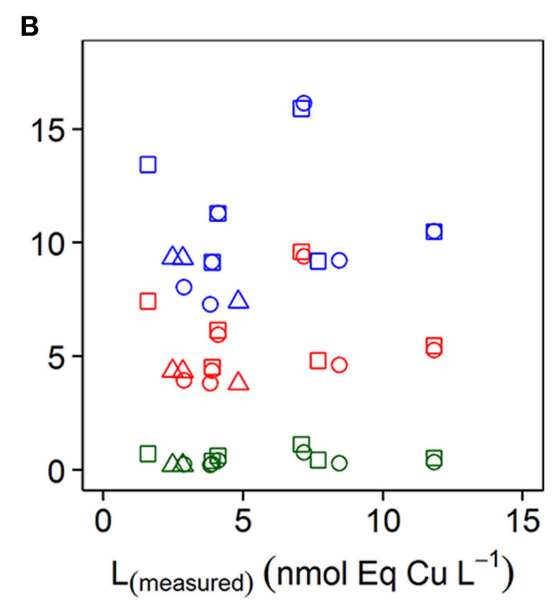

D

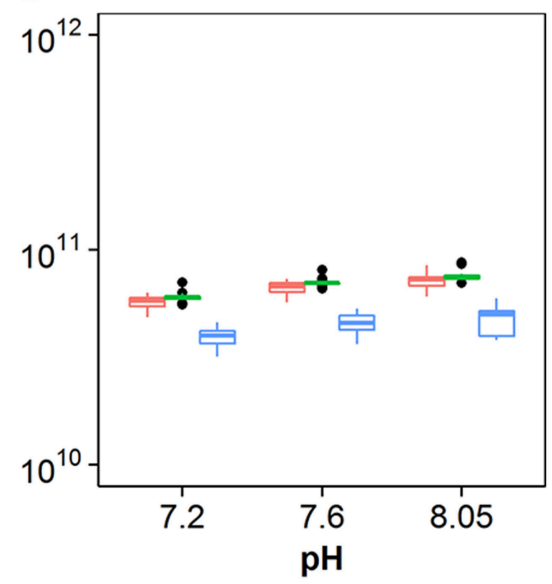

FIGURE 7 | Comparison of ligand concentrations estimated from measured $M e A L_{x}\left(L_{(m e a s u r e d)}\right.$ ) with ligand concentrations estimated from calculated

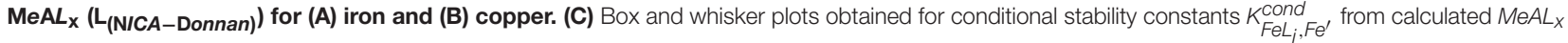
concentrations at pH 8.0, 7.6, and 7.2 for iron (C) and copper (D). The box incorporates the 25th and 75th percentiles, whilst outliers are plotted as black diamonds. The parameter sets used to obtain $M e A L_{x}$ are represented by the different colors (see legend).

the non-linear fit used for the discrete ligand approach was not significant at the $90 \%$ confidence level for many of our CLEAdCSV titrations. A simple randomized error experiment on a simulated titration suggested that incurring a random error of $5 \%$ on each titration point would result in successful fit for only 4 out of 10 titrations. (i.e., if the titration was repeated on the same sample 10 times, only 4 of the resultant datasets would predict $\log K_{\mathrm{FeL}_{i}, \mathrm{Fe}^{\prime}}^{\mathrm{cond}}$ or $L_{i, \mathrm{Fe}}$ with $>90 \%$ confidence), which is close to the number of titrations that returned $\log K_{\mathrm{FeL}_{i}, \mathrm{Fe}^{\prime}}^{\mathrm{cond}}$ and $L_{i, F e}$ for our dataset. We chose $\mathrm{HNN}$ as the added ligand because it is possible to determine iron over a relatively wide $\mathrm{pH}$ range, however undoubtedly the level of random error incurred during our titrations was exacerbated by the use of an added ligand with relatively low sensitivity (ca. $0.8 \mathrm{nA} \mathrm{nmol}^{-1}$ ), which resulted in low peak heights, even for concentrations of iron present in samples in this shelf sea study.

In the case of copper, no trend in $\log \mathrm{K}_{\mathrm{CuL}}^{\mathrm{cond}}, \mathrm{Cu}^{\prime}$ was detected with decreasing $\mathrm{pH}$ (Figure 4). This is in contrast to the previous estuarine study where a decrease of 0.7 units from $\mathrm{pH} 8.0$ to
7.2 was observed. Similarly, we did not observe any changes in $L_{i, C u}$ with a decrease in $\mathrm{pH}$, unlike the small decrease observed in Gledhill et al. (2015). Although, the number of titrations that returned $\log \mathrm{K}_{\mathrm{Cu} L_{i}, C u^{\prime}}^{\mathrm{cond}}$ and $\mathrm{L}_{i, \mathrm{Cu}}$ for our copper dataset was higher than those for iron, the use of a high detection window (10 $\mu$ M SA) affected our ability to detect any significant changes in ligand stabilities outside our selected window. A high detection window also likely affected our ability to obtain good titration fits for all our samples. $L_{i, C u}$ increased with dissolved copper concentrations and samples with the highest observed $L_{i, C u}$ were situated very close to the UK coastline (Station 7 and 8, Figure 1, Table S1).

\section{The NICA-Donnan Approach}

The addition of the added ligands to the thermodynamic database in vMINTEQ allowed us to calculate the concentrations of $M e A L_{x}$ and thus directly compare them to those determined by CLE-AdCSV. This approach thus represents an alternative for interpreting CLE experiments. The approach is more robust, in 


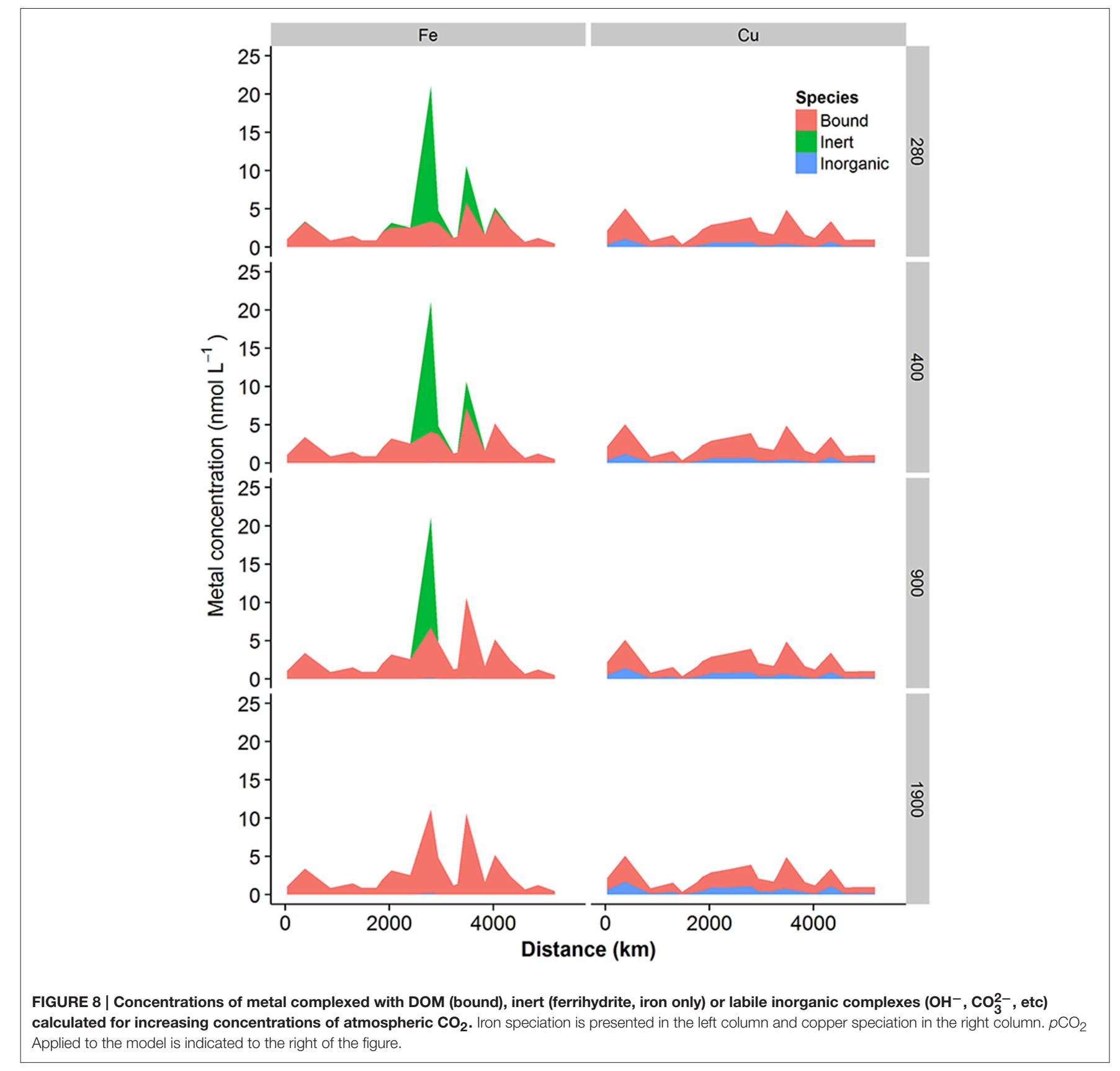

that the complete dataset could be used to optimize the model parameters. Furthermore, the software could be used to account for inert components as well as binding with DOM to give a more complete picture of metal speciation. The approach thereby overcomes some of the bias introduced by a single detection window approach (Gledhill and Buck, 2012; Pizeta et al., 2015). Our approach in this study was empirical, and further rigor could be achieved with a statistically sound optimization of the results, once basic parameters such as the number and acidity of marine DOM binding sites were known with greater certainty (e.g., Weber et al., 2006). We found that incorporation of an inert phase was required in order to calculate $\mathrm{Fe}(\mathrm{NN})_{3}$ concentrations to within an order of magnitude of measured $\mathrm{Fe}(\mathrm{NN})_{3}$ concentrations in samples with high dissolved iron (Figure 5). We examined the addition of a "strong organic fraction" as an inert phase, but this resulted in an overall reduction in calculated $\mathrm{Fe}(\mathrm{NN})_{3}$ concentration when binding sites were under saturated, followed by large increases in $\mathrm{Fe}(\mathrm{NN})_{3}$ when binding sites were saturated. This pattern of behavior did not fit the measured $\mathrm{Fe}(\mathrm{NN})_{3}$ concentrations, which were low for titration points with zero added iron even for stations 10 and 14 where initial $\mathrm{dFe}$ concentrations were 21.0 and $10.6 \mathrm{nM}$, respectively. We therefore assumed an inert phase for iron with kinetically inhibited dissolution and which was thus 


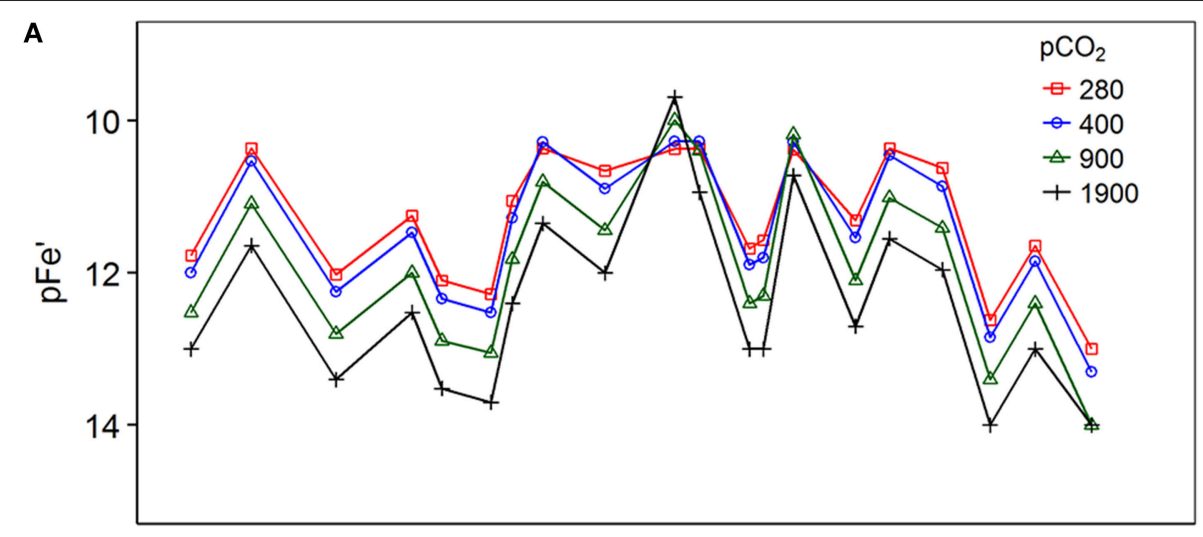

B

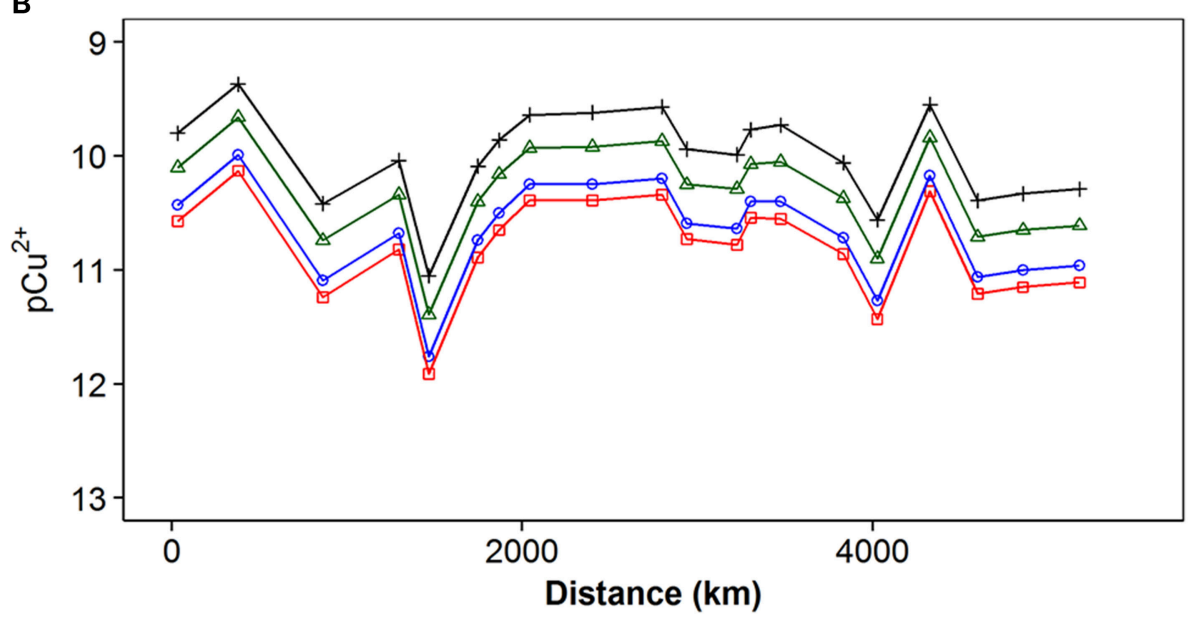

FIGURE 9 | Concentration of (A) inorganic iron expressed as pFe' (-log[Fe']) and (B) free copper expressed as pCu ${ }^{2+}\left(-\log \left[\mathrm{Cu}^{2+}\right]\right)$ calculated for different $\mathrm{pCO}_{2}$ levels from preindustrial $(280 \mu \mathrm{atm})$ to approximately five times current values (1900 $\left.\mu \mathrm{atm}\right)$.

represented through incorporation of ferrihydrite as a possible solid. Inclusion of such an inert phase would be consistent with previous studies showing that natural colloidal iron phases are unavailable for biological uptake over timescales of days (Kuma and Matsunaga, 1995; Chen and Wang, 2001). Although, observed $\mathrm{Fe}(\mathrm{NN})_{3}$ concentrations were better represented using ferrihydrite, this approach is likely an oversimplification of the true situation. Initial calculation of $\mathrm{FeNN}_{3}$ allowed the inert phase to equilibrate to the titration $\mathrm{pH}$. These initial calculations resulted in increased RMSE at lower $\mathrm{pH}$ (results not shown), and suggested that the inert fraction did not respond as iron oxyhydroxides would, if allowed to reach equilibrium. This lack of apparent response of the inert phase to changing $\mathrm{pH}$ could result from either inappropriate description of the inert phase (i.e., it is not ferrihydrite) or inappropriate experimental design (e.g., insufficient equilibration time) or both. As the inert phase did not react with our added metal, $\mathrm{pH}$ or our added ligand (at the applied detection window) it was difficult to infer any further information with respect to its solubility or nature from the experiments undertaken in this study. Other studies have shown that increasing the added ligand concentration can result in the determination of higher $\mathrm{Fe}(\mathrm{NN})_{3}$ concentrations (Hawkes et al., 2013), suggesting that NN may react with this fraction of iron at higher detection windows. It is therefore possible that the inert phase might more closely approximate a colloidal fraction of mixed organic and inorganic composition, rather than one consisting of ferrihydrite. Nevertheless, in the absence of studies that more explicitly address the chemical character of this inert phase and its solubility, we continued to use ferrihydrite as a first approximation of the inert phase.

Having settled upon our analog for the inert iron phase, further work allowed for the reduction of the RMSE between measured and calculated concentrations of $\mathrm{FeNN}_{3}$. The parameters derived in our estuarine study were found to be too strong in this respect, while those derived by Hiemstra and Van Riemsdijk (2006) too weak at low pH. We achieved our lowest RMSE with a parameter set closely resembling that of Hiemstra and Van Riemsdijk (2006), but with slightly stronger complexation at lower $\mathrm{pH}$.

For copper, we did not require an inert phase in order to describe our measured $\Sigma \mathrm{Cu}(\mathrm{HSA})_{2}$ concentrations, consistent with current knowledge of copper solubility in seawater. 
However, the $\Sigma \mathrm{Cu}(\mathrm{HSA})_{2}$ calculated for our measured data from the internal slope obtained during the CLE-AdCSV measurements were very close to the total dissolved copper concentration. Clearly an $\mathrm{H}_{2} \mathrm{SA}$ concentration of $10 \mu \mathrm{mol} \mathrm{L}{ }^{-1}$ was sufficient to outcompete most of the natural binding sites present in the samples. Although, this was unfortunate, and explains the difficulties observed when applying the discrete ligand approach (poor significance of the fits) it did place an upper constraint on the strength of the binding sites in these shelf sea waters.

We applied the discrete ligand approach to the calculated concentrations of $M e A L_{x}$ in an effort to compare the two methods. Stability constants and ligand concentrations were in good agreement with those determined from measured $M e A L_{x}$ for iron, suggesting that our NICA-Donnan parameters could reproduce the observed trends in iron complexation. However, for copper, although stability constants were similar, the variability observed in $L_{i, C u(m e a s u r e d)}$ was not observed

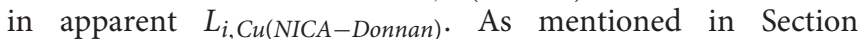
The Discrete Ligand Approach above, a trend of increasing concentrations of $L_{i, C u}$ (NICA-Donnan) with increasing dissolved $\mathrm{Cu}$ concentrations was observed, with highest concentrations at stations 7 and 8 . Stations 7 and 8 were situated in close proximity to the UK coast and also returned low conditional stability constants $\left(\log K_{C u L_{i}, C u^{\prime}}^{c o n d}=11.0-11.4\right)$ when compared to other samples in the shelf waters (Table S2). Thus, it could be that the DOM in this region of the study area had a more "terrestrial" character. In support of this, parameter sets A and $\mathrm{B}$ which were derived for estuarine and terrestrial DOM respectively (Milne et al., 2003; Gledhill et al., 2015) also resulted in higher ligand concentrations when applying the discrete ligand approach to calculated $M e A L_{x}$ concentrations (Figure 7). Alternatively, it is also possible that the application of the discrete ligand approach to the measurements on samples 7 and 8 resulted in an incorrect "local minima" in the fitting routine that underestimated $\log K_{\mathrm{Cu} L_{i}, C u^{\prime}}^{\text {cond }}$ and overestimated $L_{i, C u(m e a s u r e d)}$. This potential issue was not restricted to the Gerringa et al. (2014) routine applied here, as the same results were obtained for other available routines (e.g., ProMCC, results not shown; Pizeta et al., 2015). Such results highlight the care that needs to be applied when assessing data produced by the discrete ligand approach, especially when applying only one, potentially non-optimal detection window. In this respect, we found the NICA-Donnan approach a more robust method for interpreting CLE-AdCSV titrations.

The overall reduction in RMSE observed for parameter set C suggested that these parameters better described the whole dataset than either Set A or B. It should be stressed however, that these parameters were empirically derived and thus do not represent a true optimization of the NICA-Donnan model for marine NOCM. Set C parameters resulted in RMSEs for $M e A L_{x}$ concentrations of the same order as the measured $M e A L_{x}$ concentrations determined at the lowest point of the titration curve (i.e., when no metal had been added). The final parameters selected to describe our coastal dataset were weaker than that derived for our estuarine study for both iron and copper and it is interesting to note that this trend was observed for both metals. This could relate to a real change in binding characteristics as DOM is transported from the estuarine environment to shelf sea waters. Further, knowledge of the basic binding site characteristics of marine DOM from different environments could also potentially shed light on such changes (Muller and Bleie, 2008; Louis et al., 2009). However, it is also possible that application of the NICA-Donnan model to the interpretation of metal complexation in seawater would benefit from a changed experimental design. In particular, it would be useful to determine binding characteristics at different detection windows as well as at varying $\mathrm{pH}$. This study therefore supports recent work that suggests there is likely to be much to gain from employing a combination of titration techniques (Pizeta et al., 2015) with varied detection windows.

\section{Potential Effect of Changes in $\mathrm{PCO}_{2}$ on Iron and Copper Speciation in Coastal Waters}

The increased iron binding strength of the acidic type binding sites in the NICA-Donnan parameter set developed in this study resulted in a reverse of the trend observed previously for estuarine waters (Gledhill et al., 2015). In our shelf sea waters Fe' concentrations decreased with increasing $p \mathrm{CO}_{2}$ because binding with NOCM was stronger than ion pair interactions with hydroxides. As the NICA-Donnan parameterization of marine DOM is still in its infancy, this result must be treated with some caution. However, when both estuarine and shelf sea water studies are considered together, they do suggest that small changes in the strengths of binding sites on marine DOM can bring quite dramatic reversals in iron speciation trends with $\mathrm{pH}$. Iron binding with DOM thus appears to be finely balanced at natural seawater $\mathrm{pH}$. The trend for decreasing Fe' was reversed when $\mathrm{Fe}^{\prime}$ concentrations reached saturation and ferrihydrite precipitated (e.g., stations 10 and 14), so that at high iron concentrations, $\mathrm{Fe}$ ' concentrations increased with increasing $p \mathrm{CO}_{2}$ because the increased solubility of ferrihydrite at lower $\mathrm{pH}$ had a larger overall effect on Fe' concentrations than the decrease resulting from complexation by DOM. This could result in similar potential effect on $\mathrm{dFe}$ as that observed by Breitbarth et al. (2010). However, this increase in Fe' resulted from the use of ferrihydrite as the analog for the inert iron fraction, which as mentioned in Section The NICA-Donnan Approach, may not be entirely representative. Our results for copper were generally consistent with those observed in the previous estuarine study, even though a small refinement of the parameters defining copper binding to DOM was necessary. Thus, increased $p \mathrm{CO}_{2}$ generally results in increased $\mathrm{pCu}^{2+}$ as a result of decreased $\mathrm{CO}_{3}^{2-}$ ion concentrations.

Carbonate ion concentration, $\mathrm{pH}$, DOC and the concentrations of iron and copper varied significantly over the course of our cruise track. In addition, temperature, salinity and dissolved oxygen concentrations (Poulton et al., 2014) also varied. All of these parameters will affect metal speciation and it is beyond the scope of the present study to address the influence of the latter variables. Nevertheless, interpretation of metal speciation measurements using the NICA-Donnan or other NOCM models such as WHAM or the Stockholm Humic 
model (Ndungu, 2012; Stockdale et al., 2015) could allow for the development of a more comprehensive understanding of the interactive influence of all of these parameters on metal speciation and thus greater understanding of the link between productivity and metal biogeochemistry. For example, the highest $\mathrm{pH}$ values were observed in the Atlantic and Northern North Sea sectors of the cruise, but these high $\mathrm{pH}$ values did not clearly influence concentrations of $\mathrm{pFe}^{\prime}$ or $\mathrm{pCu}^{2+}$ because the variability in dissolved iron and copper concentrations had an overriding impact on the distribution of the metal species.

Nevertheless, increased $p \mathrm{CO}_{2}$ resulted in changes in $\mathrm{pH}$ and $\left[\mathrm{CO}_{3}^{2-}\right]$ which were ca. $4 \mathrm{x}$ times greater in magnitude than the changes observed over the cruise track. When DOM binding sites were unsaturated, this resulted in an order of magnitude decrease in $\mathrm{pFe}$ and an order of magnitude increase in $\mathrm{pCu}^{2+}$. This compared to a change in calculated $\mathrm{pFe}^{2}$ of 3 orders of magnitude and in calculated $\mathrm{pCu}^{2+}$ of approximately 2 orders of magnitude over the course of our cruise track, for a $p \mathrm{CO}_{2}$ of $400 \mu \mathrm{atm}$. Thus, as suggested previously (Gledhill et al., 2015), the natural variability in $\mathrm{pFe}^{\prime}$ and $\mathrm{pCu}^{2+}$ resulting from changes in DOC and metal concentration observed in shelf sea waters is higher than the change likely to result from increasing atmospheric $p \mathrm{CO}_{2}$. Nevertheless, our results suggest that increased $p \mathrm{CO}_{2}$ imposes a consistent chronic change in iron and copper speciation that has the potential to result in further added stress to marine microbial communities. Thus, further decreases in $\mathrm{pFe}$ ' is likely to have a biological effect when dissolved iron concentrations are low. Should open ocean iron complexation be similarly dependent on $\mathrm{pH}$, microbial communities in HNLC waters will experience lower $\mathrm{pFe}^{\text {' in the }}$ future than is currently the case. Likewise increases in $\mathrm{pCu}^{2+}$ will have the greatest impact when dissolved copper concentrations are high and microbial communities in contaminated coastal regions will potentially experience further increases in the toxic $\mathrm{pCu}^{2+}$ species as atmospheric $\mathrm{CO}_{2}$ concentrations rise.

\section{REFERENCES}

Achterberg, E. P., Holland, T. W., Bowie, A. R., Fauzi, R., Mantoura, C., and Worsfold, P. J. (2001). Determination of iron in seawater. Anal. Chim. Acta 442, 1-14. doi: 10.1016/S0003-2670(01)01091-1

Annett, A. L., Lapi, S., Ruth, T. J., and Maldonado, M. T. (2008). The effects of Cu and $\mathrm{Fe}$ availability on the growth and $\mathrm{Cu}: \mathrm{C}$ ratios of marine diatoms. Limnol. Oceanogr. 53, 2451-2461. doi: 10.4319/lo.2008.53.6.2451

Badr, E. S. A., Achterberg, E. P., Tappin, A. D., Hill, S. J., and Braungardt, C. B. (2003). Determination of dissolved organic nitrogen in natural waters using high-temperature catalytic oxidation. Trends Anal. Chem. 22, 819-827. doi: 10.1016/S0165-9936(03)01202-0

Batchelli, S., Muller, F. L. L., Chang, K. C., and Lee, C. L. (2010). Evidence for strong but dynamic iron-humic colloidal associations in humic-rich coastal waters. Environ. Sci. Technol. 44, 8485-8490. doi: 10.1021/es101081c

Benedetti, M. F., Van Riemsdijk, W. H., Koopal, L. K., Kinniburgh, D. G., Gooddy, D. C., and Milne, C. J. (1996). Metal ion binding by natural organic matter: from the model to the field. Geochim. Cosmochim. Acta 60, 2503-2513. doi: 10.1016/0016-7037(96)00113-5

Boyd, P. W., Jickells, T., Law, C. S., Blain, S., Boyle, E. A., Buesseler, K. O., et al. (2007). Mesoscale iron enrichment experiments 1993-2005: synthesis and future directions. Science 315, 612-617. doi: 10.1126/science.1131669

\section{AUTHOR CONTRIBUTIONS}

LA carried out the CLE-AdCSV titrations, interpreted the data and wrote the manuscript, $M G$ modeled the results, interpreted the data and also wrote the manuscript, EA designed the study, interpreted the data and contributed to the manuscript, VR measured $\mathrm{pH}$, interpreted the data and contributed to the manuscript, CS measured trace metals, interpreted the data and contributed to the manuscript.

\section{ACKNOWLEDGMENTS}

The authors gratefully acknowledge the reviewers for their constructive comments on the manuscript. The authors would like to thank the crew and scientists of the RRS Discovery for their assistance during the cruise, P. Lodeiro for his advice on the NICA-Donnan model and R.J.A. Rijkenberg for his help with the discrete ligand fitting routine in R. LA was funded through a CONACYT (Consejo Nacional de Ciencia y Tecnología) scholarship from the Mexican Government (Award number 179623). This work is a contribution to the UK Ocean Acidification Research Programme (UKOA), which was jointly funded by the Department for Environment, Food and Rural Affairs (DEFRA), the Natural Environment Research Council (NERC) and the Department for Energy and Climate Change (DECC) under grant agreement no. NE/H017348/1. Additional funding for modeling was provided by GEOMAR - Helmholtz Centre for Ocean Research.

\section{SUPPLEMENTARY MATERIAL}

The Supplementary Material for this article can be found online at: http://journal.frontiersin.org/article/10.3389/fmars. 2016.00058
Boye, M., Nishioka, J., Croot, P. L., Laan, P., Timmermans, K. R., and De Baar, H. J. W. (2005). Major deviations of iron complexation during 22 days of a mesoscale iron enrichment in the open Southern Ocean. Mar. Chem. 96, 257-271. doi: 10.1016/j.marchem.2005.02.002

Brand, L. E., Sunda, W. G., and Guillard, R. R. L. (1986). Reduction of marinephytoplankton reproduction rates by copper and cadmium. J. Exp. Mar. Biol. Ecol. 96, 225-250. doi: 10.1016/0022-0981(86)90205-4

Breitbarth, E., Bellerby, R. G., Neill, C., Ardelan, M. V., Meyerhofer, M., Zollner, E., et al. (2010). Ocean acidification affects iron speciation during a coastal seawater mesocosm experiment. Biogeosciences 7, 1065-1073. doi: 10.5194/bg7-1065-2010

Brewer, P. G. (1997). Ocean chemistry of the fossil fuel $\mathrm{CO}_{2}$ signal: the haline signal of "business as usual". Geophys. Res. Lett. 24, 1367-1369. doi: 10.1029/97GL01179

Buck, K. N., Moffett, J., Barbeau, K. A., Bundy, R. M., Kondo, Y., and Wu, J. (2012). The organic complexation of iron and copper: an intercomparison of competitive ligand exchange-adsorptive cathodic stripping voltammetry (CLE-ACSV) techniques. Limnol. Oceanogr. Methods 10, 496-515. doi: 10.4319/lom.2012.10.496

Byrne, R. H. (2002). Inorganic speciation of dissolved elements in seawater: the influence of $\mathrm{pH}$ on concentration ratios. Geochem. Trans. 3, 11-16. doi: 10.1186/1467-4866-3-11 
Byrne, R. H., Kump, L. R., and Cantrell, K. J. (1988). The influence of temperature and $\mathrm{pH}$ on trace-metal speciation in seawater. Mar. Chem. 25, 163-181. doi: 10.1016/0304-4203(88)90062-X

Caldeira, K., and Wickett, M. E. (2003). Anthropogenic carbon and ocean pH. Nature 425, 365-365. doi: 10.1038/425365a

Campos, M. L. A. M., and van den Berg, C. M. G. (1994). Determination of copper complexation in sea water by cathodic stripping voltammetry and ligand competition with salicylaldoxime. Anal. Chim. Acta 284, 481-496. doi: $10.1016 / 0003-2670(94) 85055-0$

Chen, M., and Wang, W. X. (2001). Bioavailability of natural colloid-bound iron to marine plankton: influences of colloidal size and aging. Limnol. Oceanogr. 46, 1956-1967. doi: 10.4319/lo.2001.46.8.1956

Clayton, T. D., and Byrne, R. H. (1993). Spectrophotometric seawater pH measurements - total hydrogen-ion concentration scale calibration of $\mathrm{m}$-cresol purple and at-sea results. Deep Sea Res. I Oceanogr. Res. Papers 40, 2115-2129. doi: 10.1016/0967-0637(93)90048-8

Croot, P. L., Moffett, J. W., and Brand, L. E. (2000). Production of extracellular $\mathrm{Cu}$ complexing ligands by eucaryotic phytoplankton in response to $\mathrm{Cu}$ stress. Limnol. Oceanogr. 45, 619-627. doi: 10.4319/lo.2000.45.3.0619

De Baar, H. J. W., Gerringa, L. J. A., Laan, P., and Timmermans, K. R. (2008). Efficiency of carbon removal per added iron in ocean iron fertilization. Marine Ecol. Progr. Ser. 364, 269-282. doi: 10.3354/meps07548

Doney, S. C. (2006). The dangers of ocean acidification. Sci. Am. 294, 58-65. doi: 10.1038/scientificamerican0306-58

Dudal, Y., and Gérard, F. (2004). Accounting for natural organic matter in aqueous chemical equilibrium models: a review of the theories and applications. Earth Sci. Rev. 66, 199-216. doi: 10.1016/j.earscirev.2004.01.002

Feely, R. A., Sabine, C. L., Lee, K., Berelson, W., Kleypas, J., Fabry, V. J., et al. (2004). Impact of anthropogenic $\mathrm{CO}_{2}$ on the $\mathrm{CaCO}_{3}$ system in the oceans. Science 305, 362-366. doi: 10.1126/science.1097329

Foo, K. Y., and Hameed, B. H. (2010). Insights into the modeling of adsorption isotherm systems. Chem. Eng. J. 156, 2-10. doi: 10.1016/j.cej.2009.09.013

Geider, R. J., and La Roche, J. (1994). The role of iron in phytoplankton photosynthesis, and the potential for iron-limitation of primary productivity in the sea. Photosyn. Res. 39, 275-301. doi: 10.1007/BF00014588

Gerringa, L. J. A., Herman, P. M. J., and Poortvliet, T. C. W. (1995). Comparison of the linear van den Berg/Ruzic transformation and a non-linear fit of the Langmuir isotherm applied to $\mathrm{Cu}$ speciation data in the estuarine environment. Mar. Chem. 48, 131-142. doi: 10.1016/0304-4203(94)00041-B

Gerringa, L. J. A., Rijkenberg, M. J. A., Thuróczy, C.-E., and Maas, L. R. M. (2014). A critical look at the calculation of the binding characteristics and concentration of iron complexing ligands in seawater with suggested improvements. Environ. Chem. 11, 114-136. doi: 10.1071/EN13072

Gledhill, M., Achterberg, E. P., Li, K., Mohamed, K. N., and Rijkenberg, M. J. A. (2015). Influence of ocean acidification on the complexation of iron and copper by organic ligands in estuarine waters. Mar. Chem. 177, 421-433. doi: 10.1016/j.marchem.2015.03.016

Gledhill, M., and Buck, K. N. (2012). The organic complexation of iron in the marine environment: a review. Front. Microbiol. 3:69. doi: 10.3389/fmicb.2012.00069

Gledhill, M., and Van Den Berg, C. M. G. (1994). Determination of complexation of iron (III) with natural organic complexing ligands in sea water using cathodic stripping voltammetry. Mar. Chem. 47, 41-54. doi: 10.1016/03044203(94)90012-4

Gledhill, M., Van Den Berg, C. M. G., Nolting, R. F., and Timmermans, K. R. (1998). Variability in the speciation of iron in the northern North Sea. Mar. Chem. 59, 283-300. doi: 10.1016/S0304-4203(97)00097-2

Guo, J., Lapi, S., Ruth, T. J., and Maldonado, M. T. (2012). The effects of iron and copper availability on the copper stoichiometry of marine phytoplankton. J. Phycol. 48, 312-325. doi: 10.1111/j.1529-8817.2012.01133.x

Gustafsson, J. P. (2001). Modeling the acid-base properties and metal complexation of humic substances with the Stockholm Humic Model. J. Colloid Interface Sci. 244, 102-112. doi: 10.1006/jcis.2001.7871

Gustafsson, J. P. (2012). Visual MINTEQ Version 3.0. Stockholm: KTH, Department of Land and Water Resources Engineering.

Hassler, C. S., Alasonati, E., Nichols, C.,a,.M., and Slaveykova, V.I. (2011). Exopolysaccharides produced by bacteria isolated from the pelagic Southern
Ocean - Role in Fe binding, chemical reactivity, and bioavailability. Mar. Chem. 123, 88-98. doi: 10.1016/j.marchem.2010.10.003

Hawkes, J. A., Gledhill, M., Connelly, D. P., and Achterberg, E. P. (2013). Characterisation of iron binding ligands in seawater by reverse titration. Anal. Chim. Acta 766, 53-60. doi: 10.1016/j.aca.2012.12.048

Hiemstra, T., and Van Riemsdijk, W. H. (2006). Biogeochemical speciation of Fe in ocean water. Mar. Chem. 102, 181-197. doi: 10.1016/j.marchem.2006.03.008

Hogle, S. L., Barbeau, K. A., and Gledhill, M. (2014). Heme in the marine environment: from cells to the iron cycle. Metallomics 6, 1107-1120. doi: $10.1039 / \mathrm{c} 4 \mathrm{mt} 00031 \mathrm{e}$

Hunter, K. A., and Boyd, P. W. (2007). Iron-binding ligands and their role in the ocean biogeochemistry of iron. Environ. Chem. 4, 221-232. doi: 10.1071/EN07012

Jacquot, J. E., Kondo, Y., Knapp, A. N., and Moffett, J. W. (2013). The speciation of copper across active gradients in nitrogen-cycle processes in the eastern tropical South Pacific. Limnol. Oceanogr. 58, 1387-1394. doi: 10.4319/lo.2013.58.4.1387

Johnson, K. S., Gordon, R. M., and Coale, K. H. (1997). What controls dissolved iron concentrations in the world ocean? Mar. Chem. 57, 137-161.

Kinniburgh, D. G., Milne, C. J., Benedetti, M. F., Pinheiro, J. P., Filius, J., Koopal, L. K., et al. (1996). Metal ion binding by humic acid: application of the NICADonnan model. Environ. Sci. Technol. 30, 1687-1698. doi: 10.1021/es950695h

Kleypas, J. A., Buddemeier, R. W., Archer, D., Gattuso, J. P., Langdon, C., and Opdyke, B. N. (1999). Geochemical consequences of increased atmospheric carbon dioxide on coral reefs. Science 284, 118-120. doi: 10.1126/science.284.5411.118

Koopal, L. K., Saito, T., Pinheiro, J. P., and Van Riemsdijk, W. H. (2005). Ion binding to natural organic matter: general considerations and the NICADonnan model. Colloids Surfaces A Physic. Eng. Aspects 265, 40-54. doi: 10.1016/j.colsurfa.2004.11.050

Kuma, K., and Matsunaga, K. (1995). Availability of colloidal ferric oxides to coastal marine phytoplankton. Mar. Biol. 122, 1-11. doi: 10.1007/BF00349272

Laglera, L. M., Battaglia, G., and Van Den Berg, C. M. G. (2007). Determination of humic substances in natural waters by cathodic stripping voltammetry of their complexes with iron. Anal. Chim. Acta 599, 58-66. doi: 10.1016/j.aca.2007.07.059

Laglera, L. M., and Van Den Berg, C. M. G. (2009). Evidence for geochemical control of iron by humic substances in seawater. Limnol. Oceanogr. 54, 610-619. doi: 10.4319/lo.2009.54.2.0610

Langdon, C., Broecker, W. S., Hammond, D. E., Glenn, E., Fitzsimmons, K., Nelson, S. G., et al. (2003). Effect of elevated $\mathrm{CO}_{2}$ on the community metabolism of an experimental coral reef. Global Biogeochem. Cycles 17:1011. doi: 10.1029/2002GB001941

Liu, X., and Millero, F. J. (1999). The solubility of iron hydroxide in sodium chloride solutions. Geochim. Cosmochim. Acta 63, 3487-3497. doi: 10.1016/S0016-7037(99)00270-7

Liu, X. W., and Millero, F. J. (2002). The solubility of iron in seawater. Mar. Chem. 77, 43-54. doi: 10.1016/S0304-4203(01)00074-3

Louis, Y., Garnier, C., Lenoble, V., Omanoviæ, D., Mounier, S., and PiŽeta, I. (2009). Characterisation and modeling of marine dissolved organic matter interactions with major and trace cations. Mar. Environ. Res. 67, 100-107. doi: 10.1016/j.marenvres.2008.12.002

Macgilchrist, G. A., Shi, T., Tyrrell, T., Richier, S., Moore, C. M., Dumousseaud, C., et al. (2014). Effect of enhanced $\mathrm{pCO}_{2}$ levels on the production of dissolved organic carbon and transparent exopolymer particles in short-term bioassay experiments. Biogeosciences 11, 3695-3706. doi: 10.5194/bg-11-3695-2014

Martell, A. E., and Smith, R. M. (2004). Critically Selected Stability Constants of Metal Complexes. Gaithersburg, MD: NIST Standard Reference Data.

Martin, J. H., and Fitzwater, S. E. (1988). Iron-deficiency limits phytoplankton growth in the Northeast Pacific Subarctic. Nature 331, 341-343. doi: $10.1038 / 331341 \mathrm{a} 0$

Millero, F. J., Woosley, R., Ditrolio, B., and Waters, J. (2009). Effect of ocean acidification on the speciation of metals in seawater. Oceanography 22, 72-85. doi: 10.5670/oceanog.2009.98

Milne, A., Landing, W., Bizimis, M., and Morton, P. (2010). Determination of Mn, $\mathrm{Fe}, \mathrm{Co}, \mathrm{Ni}, \mathrm{Cu}, \mathrm{Zn}, \mathrm{Cd}$ and $\mathrm{Pb}$ in seawater using high resolution magnetic sector inductively coupled mass spectrometry (HR-ICP-MS). Anal. Chim. Acta 665, 200-207. doi: 10.1016/j.aca.2010.03.027 
Milne, C. J., Kinniburgh, D. G., Van Riemsdijk, W. H., and Tipping, E. (2003). Generic NICA-Donnan model parameters for metal-ion binding by humic substances. Environ. Sci. Technol. 37, 958-971. doi: 10.1021/es02 58879

Moffett, J. W., and Brand, L. E. (1996). Production of strong extracellular Cu chelators by marine cyanobacteria in response to Cu stress. Limnol. Oceanogr. 41, 388-395. doi: 10.4319/lo.1996.41.3.0388

Moffett, J. W., Brand, L. E., Croot, P. L., and Barbeau, K. A. (1997). Cu speciation and cyanobacterial distribution in harbors subject to anthropogenic $\mathrm{Cu}$ inputs. Limnol. Oceanogr. 42, 789-799. doi: 10.4319/lo.1997.42.5.0789

Moore, C. M., Mills, M. M., Achterberg, E. P., Geider, R. J., Laroche, J., Lucas, M. I., et al. (2009). Large-scale distribution of Atlantic nitrogen fixation controlled by iron availability. Nat. Geosci. 2, 867-871. doi: 10.1038/ngeo667

Morel, F. M. M., and Price, N. M. (2003). The biogeochemical cycles of trace metals in the oceans. Science 300, 944-947. doi: 10.1126/science.1083545

Muller, F. L. L., and Bleie, B. (2008). Estimating the organic acid contribution to coastal seawater alkalinity by potentiometric titrations in a closed cell. Anal. Chim. Acta 619, 183-191. doi: 10.1016/j.aca.2008.05.018

Ndungu, K. (2012). Model predictions of copper speciation in coastal water compared to measurements by analytical voltammetry. Environ. Sci. Technol. 46, 7644-7652. doi: 10.1021/es301017x

Orr, J. C., Fabry, V. J., Aumont, O., Bopp, L., Doney, S. C., Feely, R. A., et al. (2005). Anthropogenic ocean acidification over the twenty-first century and its impact on calcifying organisms. Nature 437, 681-686. doi: 10.1038/nature 04095

Peers, G., Quesnel, S. A., and Price, N. M. (2005). Copper requirements for iron acquisition and growth of coastal and oceanic diatoms. Limnol. Oceanogr. 50, 1149-1158. doi: 10.4319/lo.2005.50.4.1149

Pierrot, D., Lewis, E., and Wallace, D. W. R. (2006). MS Excel Program Developed for $\mathrm{CO}_{2}$ System Calculations. ORNL/CDIAC-105a. Oak Ridge: Carbon Dioxide Information Analysis Center, Oak Ridge National Laboratory, U.S. Department of Energy. doi: 10.3334/CDIAC/otg.CO2SYS_XLS_CDIAC105a

Pizeta, I., Sander, S. G., Hudson, R. J. M., Omanovic, D., Baars, O., Barbeau, K. A., et al. (2015). Interpretation of complexometric titration data: an intercomparison of methods for estimating models of trace metal complexation by natural organic ligands. Mar. Chem. 173, 3-24. doi: 10.1016/j.marchem.2015.03.006

Poulton, A. J., Stinchcombe, M. C., Achterberg, E. P., Bakker, D. C. E., Dumousseaud, C., Lawson, H. E., et al. (2014). Coccolithophores on the north-west European shelf: calcification rates and environmental controls. Biogeosciences 11, 3919-3940. doi: 10.5194/bg-11-3919-2014

Raven, J. A., Caldeira, K., Elderfield, H., Houegh-Guldberg, O., Liss, P. S., Riebesell, U., et al. (2005). Ocean Acidification due to Increasing Atmospheric Carbon Dioxide. London: The Royal Society.

Raven, J. A., Evans, M. C. W., and Korb, R. E. (1999). The role of trace metals in photosynthetic electron transport in $\mathrm{O}_{2}$-evolving organisms. Photosyn. Res. 60, 111-149. doi: 10.1023/A:1006282714942

Rérolle, V. M. C., Floquet, C. F. A., Mowlem, M. C., Bellerby, R. R. G. J., Connelly, D. P., and Achterberg, E. P. (2012). Seawater-pH measurements for ocean-acidification observations. Trac Trends Anal. Chem. 40, 146-157. doi: 10.1016/j.trac.2012.07.016

Ribas-Ribas, M., Rérolle, V. M. C., Bakker, D. C. E., Kitidis, V., Lee, G. A., Brown, I., et al. (2014). Intercomparison of carbonate chemistry measurements on a cruise in northwestern European shelf seas. Biogeosciences 11, 4339-4355. doi: 10.5194/bg-11-4339-2014

Riebesell, U., Zondervan, I., Rost, B., Tortell, P. D., Zeebe, R. E., and Morel, F. M. M. (2000). Reduced calcification of marine plankton in response to increased atmospheric $\mathrm{CO}_{2}$. Nature 407, 364-367. doi: 10.1038/35030078
Ruzic, I. (1982). Theoretical aspects of the direct titration of natural-waters and its information yield for trace-metal speciation. Anal. Chim. Acta 140, 99-113. doi: 10.1016/S0003-2670(01)95456-X

Sander, S. G., Hunter, K. A., Harms, H., and Wells, M. (2011). Numerical approach to speciation and estimation of parameters used in modeling trace metal bioavailability. Environ. Sci. Technol. 45, 6388-6395. doi: 10.1021/es200113v

Shaked, Y., and Lis, H. (2012). Disassembling iron availability to phytoplankton. Front. Microbiol. 3:123. doi: 10.3389/fmicb.2012.00123

Shi, D. L., Xu, Y., Hopkinson, B. M., and Morel, F. M. M. (2010). Effect of Ocean Acidification on Iron Availability to Marine Phytoplankton. Science 327, 676-679. doi: 10.1126/science.1183517

Stockdale, A., Tipping, E., Hamilton-Taylor, J., and Lofts, S. (2011). Trace metals in the open oceans: speciation modeling based on humic-type ligands. Environ. Chem. 8, 304-319. doi: 10.1071/EN11004

Stockdale, A., Tipping, E., and Lofts, S. (2015). Dissolved trace metal speciation in estuarine and coastal waters: comparison of WHAM/Model VII predictions with analytical results. Environ. Toxicol. Chem. 34, 53-63. doi: 10.1002/etc.2789

Sunda, W. G., and Huntsman, S. A. (1995a). Iron uptake and growth limitation in oceanic and coastal phytoplankton. Mar. Chem. 50, 189-206.

Sunda, W. G., and Huntsman, S. A. (1995b). Regulation of copper concentration in the oceanic nutricline by phytoplankton uptake and regeneration cycles. Limnol. Oceanogr. 40, 132-137.

Tipping, E. (2005). Cation Binding by Humic Substances. Cambridge: Cambridge University Press.

Tipping, E., Lofts, S., and Stockdale, A. (2015). Metal speciation from stream to open ocean: modeling v. measurement. Environ. Chem. doi: 10.1071/en15111

Turner, D. R., Whitfield, M., and Dickson, A. G. (1981). The equilibrium speciation of dissolved components in fresh-water and seawater at 25 degrees $\mathrm{C}$ and 1 atm pressure. Geochim. Cosmochim. Acta 45, 855-881. doi: 10.1016/00167037(81)90115-0

Van Den Berg, C. M. G. (1995). Evidence for organic complexation of iron in seawater. Mar. Chem. 50, 139-157. doi: 10.1016/0304-4203(95)00032-M

Von Der Heyden, B. P., and Roychoudhury, A. N. (2015). A review of colloidal iron partitioning and distribution in the open ocean. Mar. Chem. 177, 9-19. doi: 10.1016/j.marchem.2015.05.010

Weber, C. L., Vanbriesen, J. M., and Small, M. S. (2006). A stochastic regression approach to analyzing thermodynamic uncertainty in chemical speciation modeling. Environ. Sci. Technol. 40, 3872-3878. doi: 10.1021/es0523035

Whitby, H., and Van Den Berg, C. M. G. (2015). Evidence for copperbinding humic substances in seawater. Mar. Chem. 173, 282-290. doi: 10.1016/j.marchem.2014.09.011

Yokoi, K., and Van Den Berg, C. M. G. (1992). The determination of iron in seawater using catalytic cathodic stripping voltammetry. Electroanalysis 4, 65-69. doi: 10.1002/elan.1140040113

Zeebe, R. E., and Wolf-Gladrow, D. A. (2001). CO2 in Seawater: Equilibrium, Kinetics, Isotopes. Amsterdam; New York, NY: Elsevier.

Conflict of Interest Statement: The authors declare that the research was conducted in the absence of any commercial or financial relationships that could be construed as a potential conflict of interest.

Copyright (c) 2016 Avendaño, Gledhill, Achterberg, Rérolle and Schlosser. This is an open-access article distributed under the terms of the Creative Commons Attribution License (CC BY). The use, distribution or reproduction in other forums is permitted, provided the original author(s) or licensor are credited and that the original publication in this journal is cited, in accordance with accepted academic practice. No use, distribution or reproduction is permitted which does not comply with these terms. 